\title{
Development of the HIRS Outgoing Longwave Radiation Climate Dataset
}

\author{
Hai-Tien Lee and Arnold Gruber \\ Cooperative Institute for Climate Studies/Earth System Science Interdisciplinary Center, University of Maryland, \\ College Park, College Park, Maryland \\ ROBERT G. ELLINGSON \\ Department of Meteorology, The Florida State University, Tallahassee, Florida \\ ISTVAN LASZLO \\ NOAA/NESDIS, Washington, D.C.
}

(Manuscript received 9 February 2007, in final form 19 March 2007)

\begin{abstract}
The Advanced Very High Resolution Radiometer (AVHRR) outgoing longwave radiation (OLR) product, which NOAA has been operationally generating since 1979 , is a very long data record that has been used in many applications, yet past studies have shown its limitations and several algorithm-related deficiencies. Ellingson et al. have developed the multispectral algorithm that largely improved the accuracy of the narrowband-estimated OLR as well as eliminated the problems in AVHRR. NOAA has been generating High Resolution Infrared Radiation Sounder (HIRS) OLR operationally since September 1998. In recognition of the need for a continuous and long OLR data record that would be consistent with the earth radiation budget broadband measurements in the National Polar-orbiting Operational Environmental Satellite System (NPOESS) era, and to provide a climate data record for global change studies, a vigorous reprocessing of the HIRS radiance for OLR derivation is necessary.

This paper describes the development of the new HIRS OLR climate dataset. The HIRS level $1 \mathrm{~b}$ data from the entire Television and Infrared Observation Satellite N-series (TIROS-N) satellites have been assembled. A new radiance calibration procedure was applied to obtain more accurate and consistent HIRS radiance measurements. The regression coefficients of the HIRS OLR algorithm for all satellites were rederived from calculations using an improved radiative transfer model. Intersatellite calibrations were performed to remove possible discontinuity in the HIRS OLR product from different satellites. A set of global monthly diurnal models was constructed consistent with the HIRS OLR retrievals to reduce the temporal sampling errors and to alleviate an orbital-drift-induced artificial trend. These steps significantly improved the accuracy, continuity, and uniformity of the HIRS monthly mean OLR time series. As a result, the HIRS OLR shows a comparable stability as in the Earth Radiation Budget Satellite (ERBS) nonscanner OLR measurements.

HIRS OLR has superb agreement with the broadband observations from Earth Radiation Budget Experiment (ERBE) and Clouds and the Earth's Radiant Energy System (CERES) in the ENSO-monitoring regions. It shows compatible ENSO-monitoring capability with the AVHRR OLR. Globally, HIRS OLR agrees with CERES with an accuracy to within $2 \mathrm{~W} \mathrm{~m}^{-2}$ and a precision of about $4 \mathrm{~W} \mathrm{~m}^{-2}$. The correlation coefficient between HIRS and CERES global monthly mean is 0.997 . Regionally, HIRS OLR agrees with CERES to within $3 \mathrm{~W} \mathrm{~m}^{-2}$ with precisions better than $3 \mathrm{~W} \mathrm{~m}^{-2}$ in most places. HIRS OLR could be used for constructing climatology for applications that plan to use NPOESS ERBS and previously used AVHRR OLR observations. The HIRS monthly mean OLR data have high accuracy and precision with respect to the broadband observations of ERBE and CERES. It can be used as an independent validation data source. The uniformity and continuity of HIRS OLR time series suggest that it could be used as a reliable transfer reference for the discontinuous broadband measurements from ERBE, CERES, and ERBS.
\end{abstract}

Corresponding author address: Hai-Tien Lee, CICS/ESSIC-NOAA, University of Maryland, College Park, 4115 Computer and Space Bldg. \#224, College Park, MD 20742.

E-mail: lee@essic.umd.edu

DOI: $10.1175 / 2007 J T E C H A 989.1$

(C) 2007 American Meteorological Society 


\section{Introduction}

In the late 1980s Ellingson et al. (1989) successfully developed a multispectral regression technique using the radiance observations from the High Resolution Infrared Radiation Sounder (HIRS) to estimate the outgoing longwave radiation (OLR) at the top of the atmosphere. Acknowledging its better accuracy and other advantages over the long-standing National Oceanic and Atmospheric Administration (NOAA) Advanced Very High Resolution Radiometer (AVHRR) OLR, which is estimated from a single atmospheric window measurement, NOAA/National Environment Satellite, Data, and Information Services (NESDIS) implemented the HIRS OLR algorithm and has been operationally generating the HIRS OLR product since September 1998. The National Polar-orbiting Operational Environmental Satellite System (NPOESS), scheduled for its first launch in the early 2010s, is the next generation of environmental/weather polarorbiting satellites. It continues and expands the missions and functions of the current NOAA polar operational environmental satellites (POES), that is, the Television Infrared Observation Satellite N-series (TIROS-N) satellites. On NPOESS, the earth radiation budget parameters were initially planned to be produced by the Earth Radiation Budget Sensor (ERBS), which is essentially the Clouds and the Earth's Radiant Energy System (CERES; Wielicki et al. 1996) currently flying on the National Aeronautics and Space Administration (NASA) Earth Observing System (EOS) Terra and Aqua satellites. (As of June 2006, the revised NPOESS plan uses the spare CERES Flight Model 5 to substitute the ERBS instrument, and only one earth radiation budget instrument will be flown in the NPOESS series.) AVHRR OLR users, for example, the Climate Prediction Center (CPC) at the National Centers for Environmental Prediction (NCEP), require the history of a long data record for climate-monitoring purposes. Being on experimental satellites, CERES does not possess a long enough data record for the latter purposes. AVHRR OLR users who plan to advance their applications into the NPOESS era would need an OLR data record that is as extended as AVHRR but also compatible with the ERBS product. Recognizing that the HIRS OLR can serve this purpose well, we have reprocessed the HIRS level $1 \mathrm{~b}$ data and have derived the HIRS OLR data record for the entire TIROS-N series satellites from 1979 to present.

Since HIRS is on the operational NOAA satellites, we faced some challenges to maintain the continuity and homogeneity for the HIRS OLR time series, particularly the orbital drift and the varying instrument specifications. The insufficient number of observations available for a given location within a day is the intrinsic difficulty for deriving accurate daily mean OLR from the NOAA polar orbiters. In addition to that, when the observations were not made at fixed local times, it introduced biases aliased into the time series. We have carefully examined each of the problems and developed methods to minimize their impacts. The purpose of this paper is to describe in detail the steps toward the development and generation of the HIRS OLR time series.

The HIRS level $1 \mathrm{~b}$ data, which will be described in the next section, is the raw input data for the generation of the HIRS OLR time series. Sections that describe the critical steps toward the generation of the HIRS OLR time series, including the derivation the coefficients for the OLR algorithm, the radiance calibration, the intersatellite calibration, and the empirical diurnal modeling follow this. Results from the intercomparison of several satellite OLR products will be discussed.

\section{HIRS level 1b data}

The HIRS is one of three sounding instruments of the TIROS Operational Vertical Sounder (TOVS) system on board the NOAA TIROS-N satellites. The detailed description of HIRS level $1 \mathrm{~b}$ data, the TOVS system, and the NOAA TIROS-N polar orbiters can be found in the NOAA Polar Orbiter Data (POD) user's guide (NOAA 2006a) and the NOAA KLM user's guide (NOAA 2006b).

Calculation of OLR from HIRS radiance observations requires the knowledge of the local zenith angle (LZA) at each HIRS field of view (FOV). Prior to NOAA-K, the HIRS level $1 \mathrm{~b}$ data did not store LZA for all FOVs but just the first spot of each scan line (out of total 56 FOVs). The full accurate derivation of LZA requires a navigation package, for example, the Advanced Earth Location Data System (AELDS), and raw satellite data prior to level $1 \mathrm{~b}$. Because of large data volume, software availability, and processing load, the complete reprocessing of level $1 \mathrm{~b}$ data under this project is insurmountable. A method was therefore devised to approximate the LZA without revisiting the full navigation derivations. Figure 1 illustrates the satellite-viewing geometry. With the Law of Sines and with the given specification of the scanner's constant stepping increment at $1.8^{\circ}$, assuming that the satellite height and the compensation for satellite maneuvers remain constant during one scan line, we calculate the LZA for the $i$ th scanning spot by

$$
\theta_{i}=\sin ^{-1}\left[\frac{R\left(\delta_{\text {nadir }}\right)+H}{R\left(\delta_{i}\right)} \sin \left(\phi_{i}+\varepsilon\right)\right],
$$




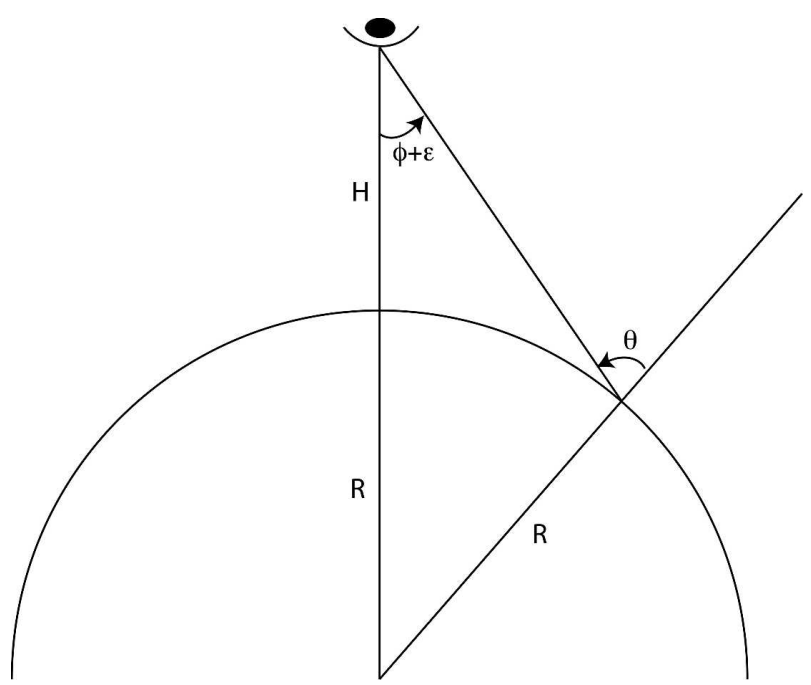

FIG. 1. Satellite view geometry: $R$ is earth radius, $H$ is satellite altitude, $\theta$ is local zenith angle, $\phi$ is satellite-view angle determined by the scanning mirror, and $\varepsilon$ is the compensation in satellite-view angle due to satellite's roll, pitch, and yaw.

where $\delta_{\text {nadir }}$ is the latitude of the subsatellite point, $\phi_{\mathrm{i}}$ is the satellite view angle, $\delta_{i}$ is the geocentric latitude for $i$ th spot, and $H$ is the satellite altitude. Based on the given LZA of the first scanning spot at latitude $\delta_{1}$, the compensation angle $\varepsilon$ was derived by

$$
\varepsilon=\sin ^{-1}\left[\frac{R\left(\delta_{1}\right)}{R\left(\delta_{\text {nadir }}\right)+H} \sin \left(\theta_{1}\right)\right]-\phi_{1} .
$$

The earth radius $R$ was calculated consistent with NESDIS as

$$
R\left(\delta_{i}\right)=R_{e} \frac{1-f}{\sqrt{1-e^{2} \cos ^{2} \delta_{i}}},
$$

where the earth radius at the equator $R_{e}=6378.135$ $\mathrm{km}$, the flattening coefficient $f=1 / 298.25$, and the eccentricity $e=f(2-f)$.

We used a set of 1008 scan lines from NOAA-16 to evaluate the LZA reconstruction method. The maximum difference between the estimated and the navigated LZAs is about $0.7^{\circ}$, occurring at scans near the South Pole. The mean error is about $-0.04^{\circ}$ with a standard deviation of $0.14^{\circ}$.

We assembled the HIRS level $1 \mathrm{~b}$ dataset for the entire TIROS-N series from several sources. The primary sources are the NOAA/NESDIS Satellite Active Archive (SAA) and National Climatic Data Center (NCDC) Comprehensive Large Array-data Stewardship System (CLASS). The TOVS Radiance Pathfinder Project (Jackson et al. 2003) at the NOAA/ Environmental Technology Laboratory (ETL) pro- vided additional NOAA-9 HIRS level $1 \mathrm{~b}$ data for December 1984 to February 1985. These NOAA-9 data, which were not available at NCDC, provide the overlap between NOAA-7 and NOAA-9 so that we were able to achieve the intersatellite calibration for the entire data record of the TIROS-N satellites. Table 1 lists the HIRS level $1 \mathrm{~b}$ data and their temporal coverage assembled for this study. The total archive size of the HIRS level $1 b$ data up to year 2003 is about $1.3 \mathrm{~Tb}$.

\section{Generation of HIRS OLR time series}

We generated the global, $2.5^{\circ} \times 2.5^{\circ}$, monthly mean HIRS OLR time series for January 1979 to September 2003. The following sections explain the HIRS OLR retrieval algorithm, HIRS radiance calibration, intersatellite calibration, and the empirical OLR diurnal models.

\section{a. HIRS OLR algorithm}

Ellingson et al. (1989) developed the multispectral regression technique to estimate the top-of-theatmosphere OLR using the HIRS radiance observations. This algorithm has been validated with the Earth Radiation Budget Experiment (ERBE) broadband measurements (Ellingson et al. 1994). It was further adapted for the Geostationary Operational Environmental Sounder (GOES) and validated successfully against the CERES broadband measurements (Ba et al. 2003). It was also adapted for the GOES Imager by Lee et al. (2004a), and that algorithm has been implemented at NESDIS in operational GOES Surface and Insola-

TABle 1. Description of HIRS instrument type and level $1 \mathrm{~b}$ dataset coverage assembled for this study.

\begin{tabular}{lcc}
\hline \hline Satellite & Period & Instrument type \\
\hline TIROS-N & 1978 day 294-1980 day 054 & HIRS/2 \\
NOAA-6 & 1979 day 181-1983 day 064 & HIRS/2 \\
& 1985 day 098-1985 day 181 & \\
1985 day 290-1986 day 319 & \\
NOAA-7 & 1981 day 236-1985 day 032 & HIRS/2 \\
NOAA-8 & 1983 day 123-1984 day 163 & HIRS/2 \\
& 1985 day 182-1985 day 287 & \\
NOAA-9 & 1984 day 348-1988 day 312 & HIRS/2 \\
NOAA-10 & 1986 day 329-1991 day 259 & HIRS/2 \\
NOAA-11 & 1988 day 313-1995 day 100 & HIRS/2I \\
& 1997 day 196-2000 day 117 & \\
NOAA-12 & 1991 day 259-1998 day 348 & $\mathrm{HIRS} / 2$ \\
NOAA-14 & 1995 day 001-2003 day 273 & $\mathrm{HIRS} / 2 \mathrm{I}$ \\
NOAA-15 & 1998 day 299-2002 day 297 & $\mathrm{HIRS/3}$ \\
NOAA-16 & 2001 day 001-2003 day 243 & $\mathrm{HIRS} / 3$ \\
NOAA-17 & 2002 day 191-2003 day 243 & $\mathrm{HIRS/3}$ \\
\hline
\end{tabular}


tion Project (GSIP) production (I. Laszlo 2005, personal communication).

The OLR can be estimated from the HIRS radiances observed at local zenith angle $\theta$ as

$$
\mathrm{OLR}=a_{0}(\theta)+\sum_{i=1}^{4} a_{i}(\theta) N_{i}(\theta)
$$

where $a_{0}$ and $a_{i}$ are regression coefficients and $N_{i}$ is the HIRS radiance from channel $i$. The HIRS channels chosen for OLR estimation from TIROS-N, NOAA-6, $-7,-8,-9,-10$, and -12 are channels $3,7,10$, and 12 (14.4, $13.3,8.2$, and $6.7 \mu \mathrm{m}$, respectively). They are channels $3,10,11$, and 12 for NOAA-11, -14, -15,-16,-17, and -18 . The change in the channel combination was forced by the modification in the HIRS channel 10 spectral locations on HIRS/2I, HIRS/3, and HIRS/4 instruments. Physically, these channels provide temperature and water vapor information in the upper and lower portions of the troposphere. The regression rms errors are zenith angle dependent and range from about 1 to $5 \mathrm{~W} \mathrm{~m}^{-2}$.

There are several variants of the HIRS instrument throughout the history of the TIROS-N satellites: HIRS/2 on board TIROS-N, NOAA-6-10, and NOAA12; HIRS/2I on board NOAA-11 and NOAA-14; HIRS/3 on board NOAA-15-17 (KLM); and HIRS/4 on board the current $N O A A-18(\mathrm{~N})$. There was a major modification in the HIRS/2I: the lower-tropospheric water vapor channel of HIRS/2 (channel 10 at about 8.2 $\mu \mathrm{m}$ ) was eliminated and replaced by a channel at about $12.6 \mu \mathrm{m}$ (still labeled as channel 10 on HIRS/2I and the following HIRS/3 and HIRS/4). Although the NOAA POD User's Guide still attributes HIRS/2I channel 10 for water vapor sensing purposes, it is actually very sensitive to the near-surface temperature. The original HIRS OLR algorithm design was modified to reflect the change in HIRS instrument. This may alter the characteristics of the HIRS OLR product and introduce discontinuity in the time series. Its effects were noticed during the intersatellite calibration and other analyses.

To ensure uniformity and to improve the accuracy of OLR estimate, we rederived the regression coefficients for each of the HIRS/2, HIRS/2I, and HIRS/3 instruments of the TIROS-N satellites with an improved radiative transfer model calculated at a finer resolution in zenith angle (see the appendix).

We used the Warner and Ellingson (2000) radiative transfer model (hereafter referred to as the WE model) to simulate the OLR and HIRS radiance following Ellingson et al. (1989). The WE model improved the Ellingson and Gille (1978) model in several aspects. It included a new technique that improved the traditional
Malkmus statistical model to calculate water vapor line transmittance, and it included the water vapor continuum in a manner consistent with the water vapor line absorption. The WE model also has a greater number of spectral intervals, 305 versus 140 bands, and therefore a finer resolution, mostly $5 \mathrm{~cm}^{-1}$ across the $0-3000$ $\mathrm{cm}^{-1}$ thermal infrared spectrum.

In the past, partly due to the constraint of computation power, the radiative transfer model calculations were performed at just a few local zenith angles. We calculated the HIRS radiance at every $5^{\circ}$ from $0^{\circ}$ to $65^{\circ}$ so that the OLR coefficients would be subject to less interpolation errors.

\section{b. Radiance calibration}

The calibration from photometric count to the physical radiance unit is the first and very important step for achieving accurate and consistent HIRS OLR retrieval. We chose the radiance calibration procedure developed by L. McMillin for reprocessing the HIRS radiance data (appendix M of NOAA 2006a). For completeness, we provide below some key information about the advantages of this calibration procedure.

A superswath of HIRS level 1b data has 43 scan lines where lines 1-3 and 41-43 are calibration scans that start with a space-view scan, followed by a coldblackbody-view scan and a warm-blackbody-view scan, and lines 4-40 are earth-view scans. The original HIRS calibration procedure uses the fixed calibration coefficients calculated from the last calibration scans on the first half scans of a superswath and those calculated from the following calibration scans on the second half of the superswath. That method caused a jump in the values of the brightness temperature at the center of a superswath and it does not take into consideration the change of the environmental temperatures through a superswath. The calibration procedure used here bases the calibration on the information from calibration scans at both ends of a superswath but also takes into account the change of the environment temperatures.

NESDIS provided the satellite-specific coefficients for estimating the brightness temperature adjustment with respect to the environment temperature changes (L. McMillin 2003, personal communication). The detailed description of the calibration procedure and FORTRAN codes are available in the appendix $\mathrm{M}$ of NOAA (2006a) and are available online (see http:// www2.ncdc.noaa.gov/docs/podug/html/m/app-m.htm).

\section{c. Intersatellite calibration}

We developed an intersatellite calibration method to eliminate the possible discontinuity in the OLR time 


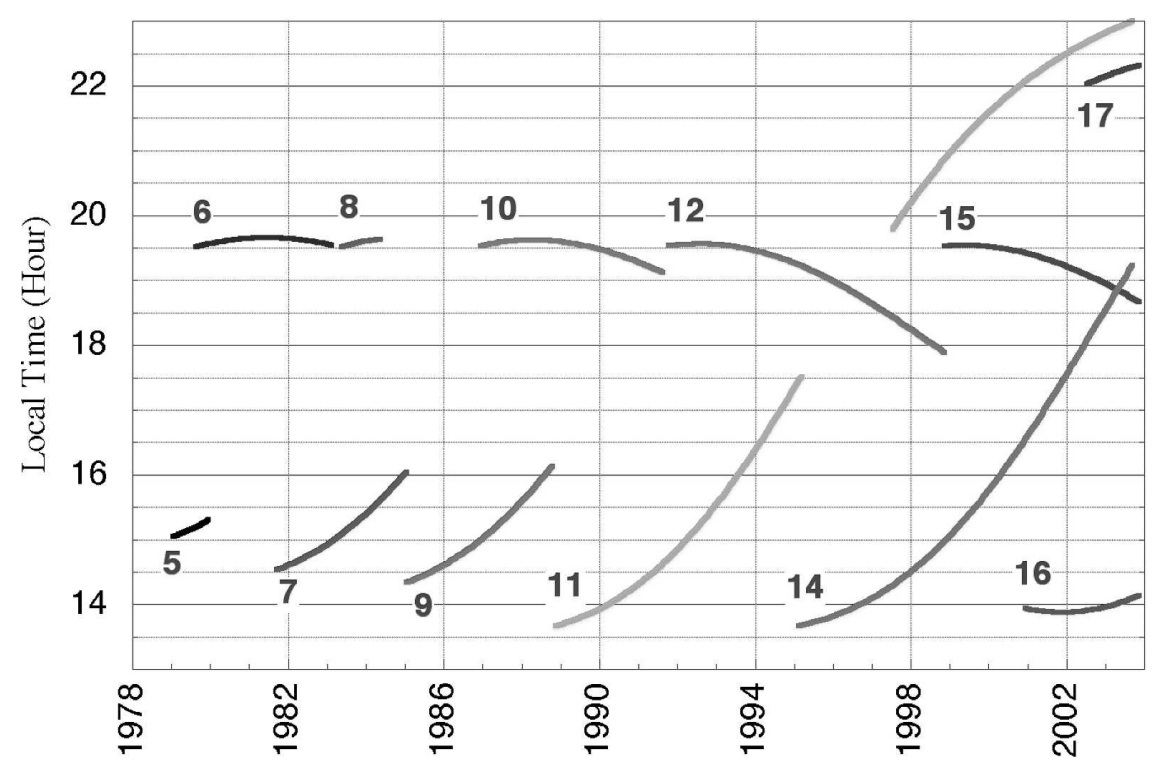

FIG. 2. Temporal span of the TIROS-N satellites and their equator crossing time for the ascending orbit.

series derived from different satellites. The possible sources of errors that caused such discontinuity include the error in the prelaunch characterization and postlaunch shift/change of the instrument response functions, radiance calibration biases, satellite navigation errors, etc.

Figure 2 shows the temporal span of the TIROS-N satellites and their equator crossing time (ECT) for the ascending orbit. Typically, there is an extensive overlap between a morning satellite (initial ECT at around 1430/0230 LT.) and an afternoon satellite (initial ECT at around 1930/0730 LT). The exceptions are the TIROS-N satellite (labeled with number 5) and $N O A A-8$ that both suffered unexpected early termination. The long-lived satellites, for example, NOAA-11 and $N O A A-14$, provided extra overlap with other satellites.

The best collocation data for examining the retrieval consistency between two satellites are those retrieved for the same field of view, at the same observing time, and with the same viewing geometry. Except for the nadir condition, these requirements are very hard to meet for the NOAA polar orbiters, particularly in the viewing geometry because of the near-perpendicular orbital crossing between an afternoon and a morning satellite. Therefore, for each overlapping satellite pair, we collocated the OLR retrievals observed within \pm 30 $\min$ in a $2.5^{\circ} \times 2.5^{\circ}$ area regardless of the satelliteviewing geometry. To ensure that the samples were taken from uniform scenes, we devised a homogeneity filter that excludes cases when the standard error of the regional mean OLR from either satellite is larger than $1 \mathrm{~W} \mathrm{~m}^{-2}$. Figure 3 shows an example of the normalized distribution of the OLR differences of the collocated data for the pair of NOAA-9 and NOAA-10. The distributions of OLR retrieval differences for either all or uniform scenes are approximately Gaussian with almost identical mean differences but with different degree of spreads, suggesting scene-dependent random sampling noises. This indicates consistent OLR retrievals from the two satellites but with a systemwide bias. The smaller spread in the uniform scenes suggested that the homogeneity filtering procedure has successfully excluded the mismatched scenes and produced more

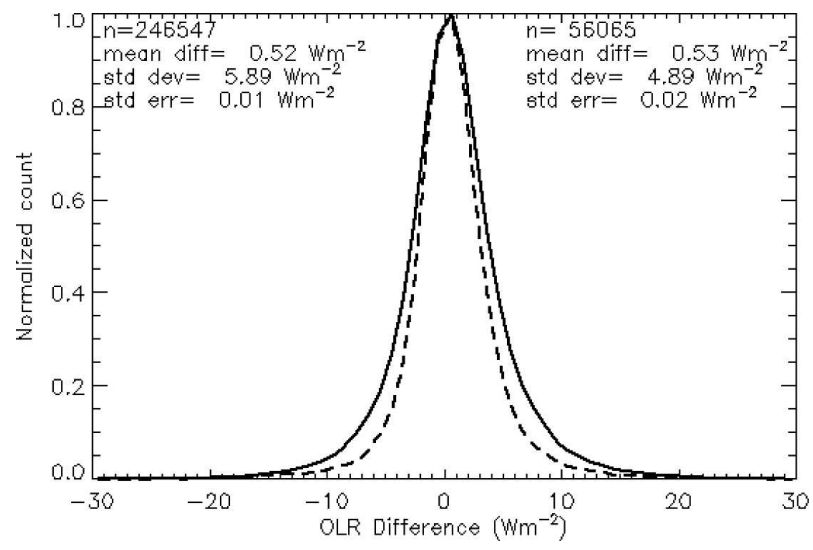

FIG. 3. Normalized distribution of the OLR differences of the collocated data, NOAA-10 minus NOAA-9. The solid line corresponds to collocation data from all scenes, and the dashed line is for the uniform scenes. 
confident statistics. The mean OLR differences determined from uniform scenes for each overlapping satellite pair defined the systemwide biases. With the large sample sizes (about 20 000-60000 collocated retrievals), the confidence is high that the standard errors of the mean differences are just a few hundredths watts per meter squared. We chose NOAA-9 as the reference satellite for intersatellite calibration purpose since NOAA-9 HIRS OLR has been extensively validated against ERBE broadband measurements (Ellingson et al. 1994). Table 2 shows the OLR biases determined successively from the intersatellite calibration results. Subtracting these adjustment amounts from the OLR retrievals of the corresponding satellites produced a homogenous and continuous HIRS OLR time series.

An alternative intersatellite calibration method defined a linear relationship including an intercept and a slope terms between two satellites' OLR retrievals. Since the tracks of the morning and afternoon satellites overlap only at high latitudes, the values of collocated OLR do not have the full extent of OLR values in a global coverage but mostly distributed over the middle to low ends. The slope term determined from such subset samples might not be representative and it might inadvertently introduce large errors when the linear relationship extrapolates into regions with higher OLR values.

During the intersatellite calibration exercise, we noticed a problem seemingly related to the continuity of instruments and consistency of the OLR algorithm. As mentioned earlier there is a major modification on HIRS/2I. We noticed that the distributions of the OLR differences between any pairs of a HIRS/2 and a HIRS/ 2I were not as well behaved as in other satellite pairs. Figure 4 shows the distribution of OLR differences of NOAA-12-NOAA-11. It indicated that the OLR estimates between these two types of instruments might not be as consistent as expected. Detailed examination

TABLE 2. OLR biases determined successively from the intersatellite calibration results choosing $N O A A-9$ as the reference satellite.

\begin{tabular}{cc}
\hline \hline Satellite & Bias $\left(\mathrm{W} \mathrm{m}^{-2}\right)$ \\
\hline NOAA-5-NOAA-9 & 0.15 \\
NOAA-6-NOAA-9 & 1.80 \\
NOAA-7-NOAA-9 & 2.13 \\
NOAA-8-NOAA-9 & 2.03 \\
NOAA-10-NOAA-9 & 0.53 \\
NOAA-11-NOAA-9 & -5.36 \\
NOAA-12-NOAA-9 & -2.42 \\
NOAA-14-NOAA-9 & -5.14 \\
NOAA-15-NOAA-9 & -3.65 \\
NOAA-16-NOAA-9 & -3.25 \\
\hline
\end{tabular}

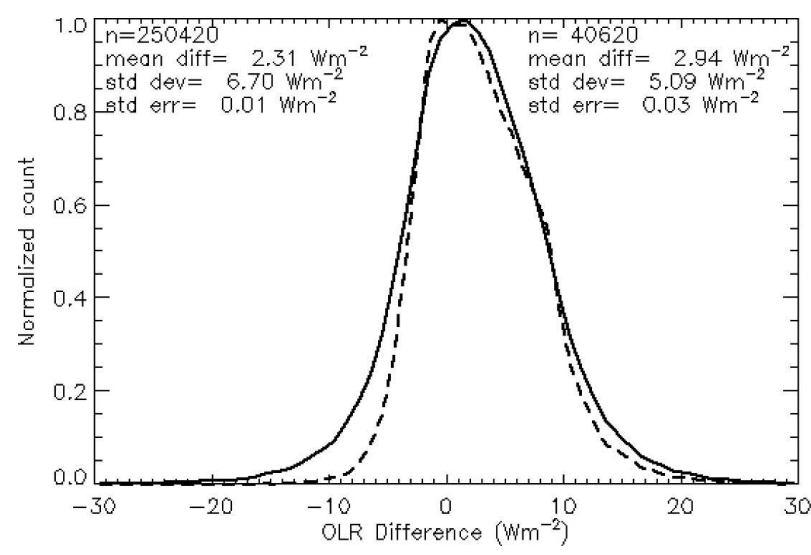

FIG. 4. Similar to Fig. 3, but for NOAA-12 minus NOAA-11.

of the algorithm and other evidence suggested that the inclusion of channel 10 of HIRS/2I and HIRS/3 instruments might have caused the algorithm to inaccurately estimate the contribution from the surface emission. There is another concern that involves channel 12 of the HIRS/3 instruments. That channel was shifted slightly toward the center of the $6.3-\mu \mathrm{m}$ water vapor band that causes it to be sensitive to water vapor variation at a relatively higher altitude. This might change the HIRS OLR's sensitivity to the upper-tropospheric humidity (UTH) variation. Although the collocated OLR between the HIRS/2I and HIRS/ 3 instruments seemed to be consistent, the small differences in the UTH sensitivity might simply be dwarfed by the dominant sensitivity of the surface contribution in the all-sky conditions. These issues need to be addressed in future algorithm revisions.

\section{d. Empirical diurnal model}

The range of OLR diurnal variations could reach more than $180 \mathrm{~W} \mathrm{~m}^{-2}$. Persistent large OLR diurnal variations can be found over regions with strong convection over the oceans and over most of the land. Figure 5 shows an example of the range of the OLR diurnal variation calculated from GOES Imager retrieval for 7 August 2002 (Lee et al. 2004b). Insufficient temporal sampling of the NOAA polar orbiters may affect the accuracy of the daily mean OLR estimate. As seen in Fig. 2 there are some periods (1979-81 and 1984-86) that only one satellite was providing observations, although most of the time there are two. Ellingson and $\mathrm{Ba}$ (2003) estimated that the RMS error in 24-h average daily mean due to temporal sampling alone is about $7 \mathrm{~W} \mathrm{~m}^{-2}$ with 6-hourly observations, while this error is nearly doubled if only 12 -hourly observations were available. 


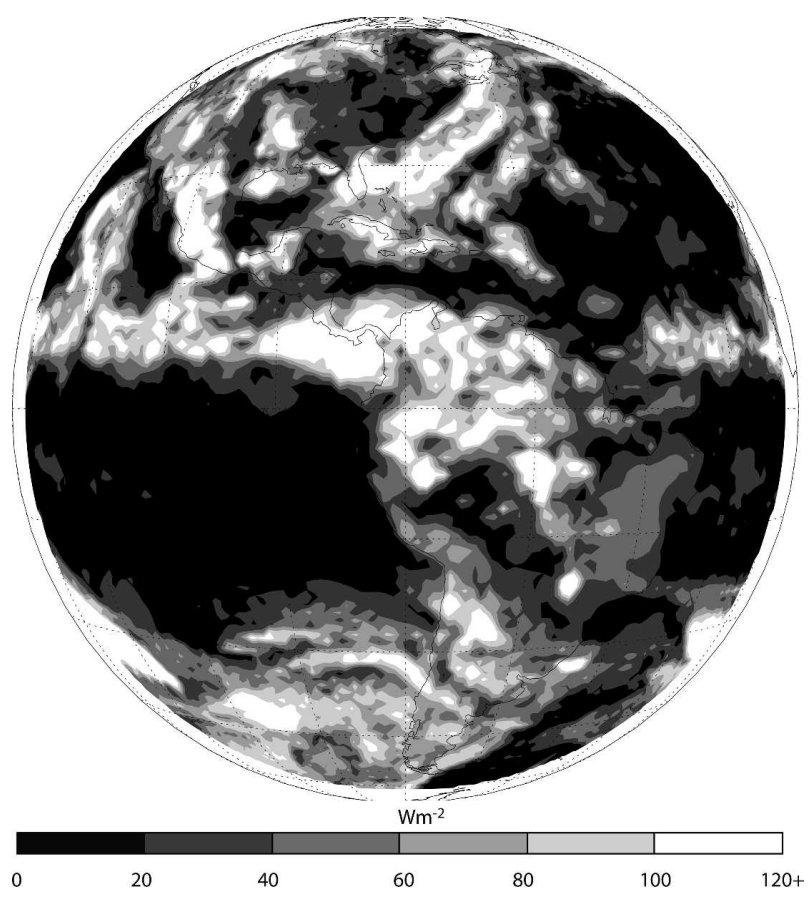

FIG. 5. Range of OLR diurnal variation for 7 Aug 2002 estimated by GOES Imager OLR

The TIROS-N satellites also have a rather large magnitude orbital drift, particularly in the afternoon satellites. The orbital drift poses a problem for the HIRS OLR time series because it introduces artificial trends (Jacobowitz et al. 2003). On the other hand, it provides the opportunity for extracting information of the OLR diurnal variation.

To minimize the impact of these two problems, we developed an empirical diurnal model similar to that of Gruber and Chen (1988). The empirical diurnal model was developed based on the $25 \mathrm{yr}$ of intersatellite calibrated HIRS OLR retrievals averaged at the respective observation time in each $2.5^{\circ} \times 2.5^{\circ}$ area for each month. The diurnal model was formulated as a modified second order Fourier expansion as

$$
\mathrm{OLR}=a_{0}+a_{1} \cos \frac{\pi\left(t-t_{0}\right)}{12}+a_{2} \cos \frac{2 \pi\left(t-t_{0}\right)}{12}
$$

where $t$ is the observation local time. The coefficients $a_{0}, a_{1}, a_{2}$ and the phase $\mathrm{t}_{0}$ are determined from least squares regression.

The second harmonic term was chosen to be fixed at the same phase as in the first harmonic because this seemed to better describe the envelop of the OLR diurnal variations and avoids multiple-peak diurnal model when the distribution of observation times are not sufficiently even. Figure 6 shows the examples of the January OLR diurnal models for the Sahara Desert and Tsaidam basin. Tsaidam basin happened to be the best-case scenario; the empirical diurnal model explained $92 \%$ of OLR variances with a fitting error of only about $4 \mathrm{~W} \mathrm{~m}^{-2}$. The regression residuals could come from imperfect modeling as well from the natural interannual variation. Since the magnitude of interannual variation is usually several times smaller than that of the OLR diurnal variation, particularly over the land, the determination of the climatological diurnal variation envelop would be rather robust assuming there is no strong correlation between the interannual variation and the orbital drift. The OLR monthly means were then determined by the 24-h integral of the diurnal models fitted to the monthly averaged local time OLR retrievals, allowing the scaling of the amplitudes.

Figure 7 shows the maps of explained variances of the OLR diurnal variations and the regression fitting errors by the empirical diurnal models for January as an
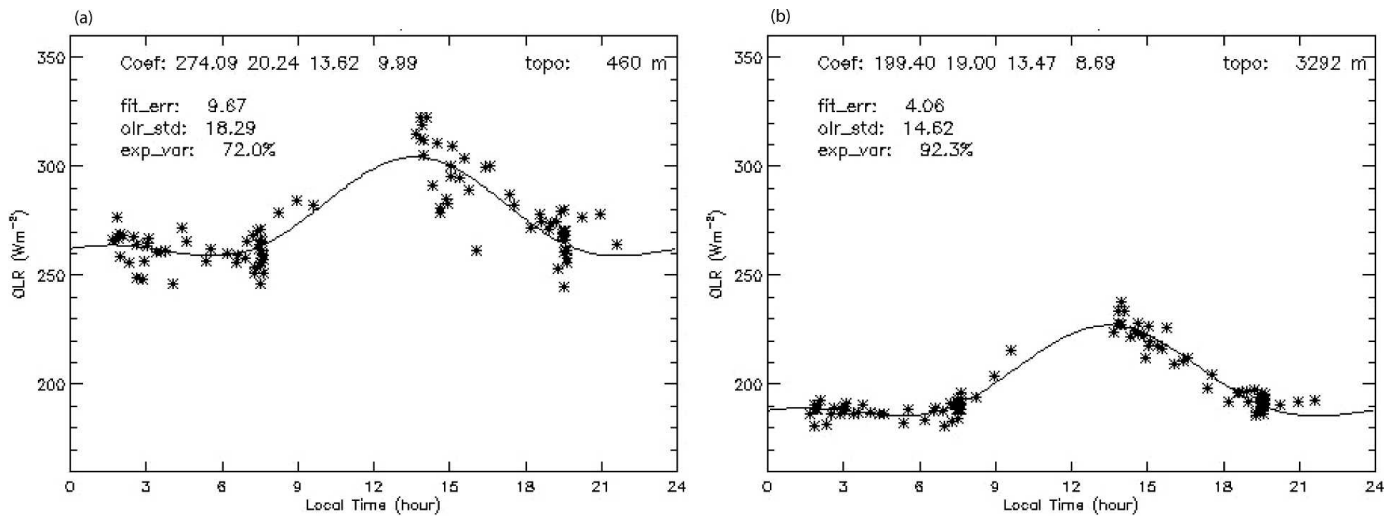

FIG. 6. Examples of OLR diurnal model fitted for the (a) Sahara Desert and (b) Tsaidam basin for January. 
(a)

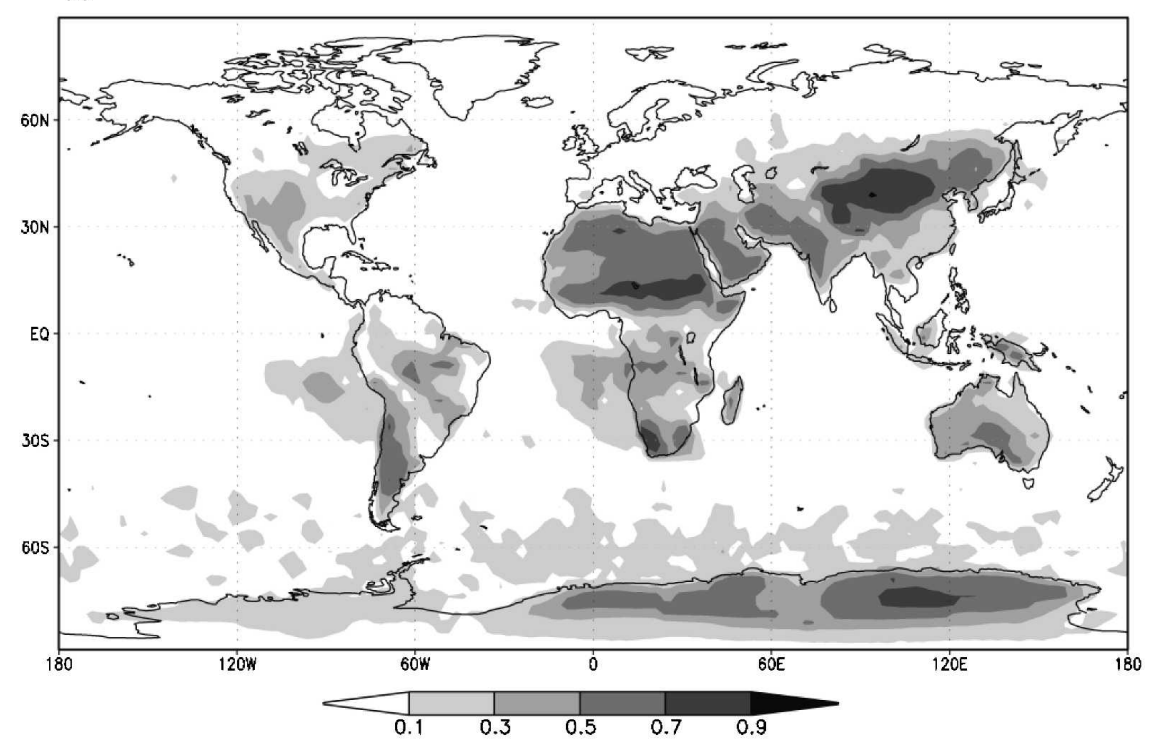

(b)

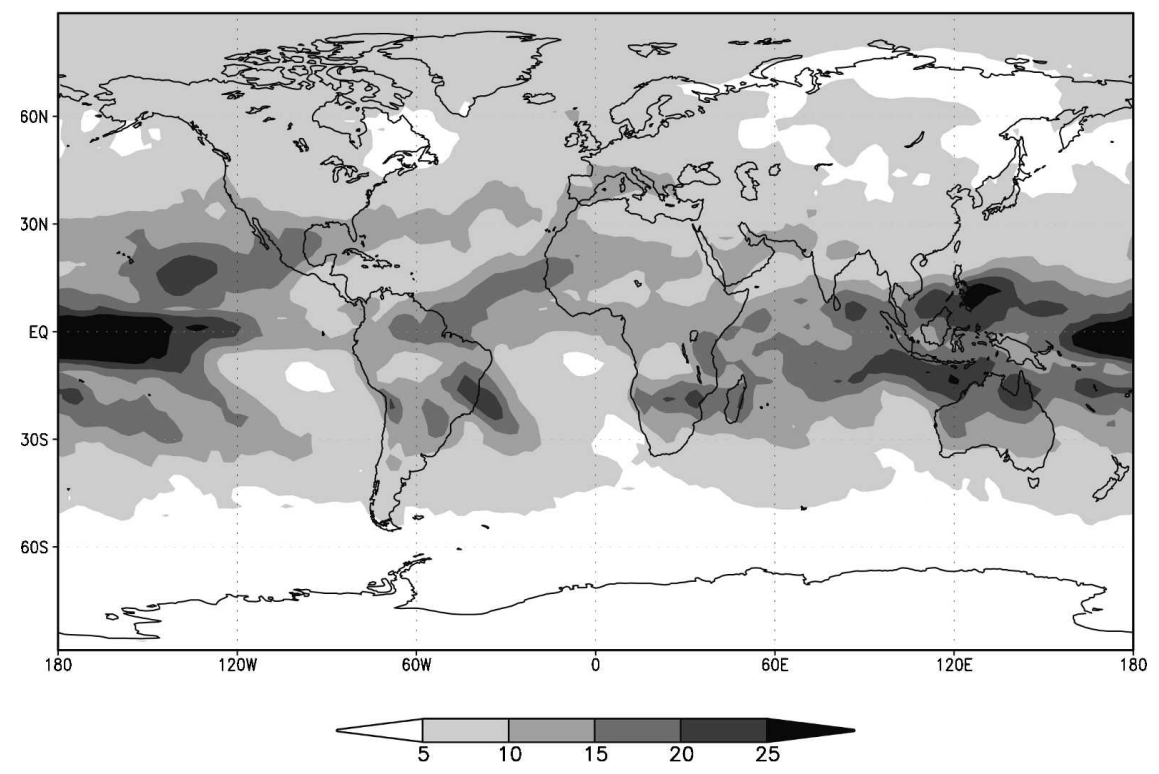

FIG. 7. (a) Explained variances (\%) of OLR diurnal variations and (b) the fitting errors $\left(\mathrm{W} \mathrm{m}^{-2}\right)$ of the empirical diurnal model for January.

example. It can be seen that the diurnal models are capable of reducing temporal integration errors over most of the land areas, especially the desert and elevated regions. Since the diurnal models were derived by compositing the different local time observations from all years, we assumed that the magnitude of the interannual variations are much smaller than that of the diurnal variation. The explained variance maps indirectly validated this assumption for the land application. The OLR diurnal variation over most of the ocean is relatively small. The low explained variance of the diurnal model over most of the oceans suggested that the oceanic OLR interannual variation and diurnal variation might be at a comparable or even larger magnitude. Persistent diurnal variations seem to be present in some oceanic areas, for example, in the tropical oceans by the west coast of America and Africa continents, and were captured by the diurnal models to various degrees. The fitting errors (Fig. 7b) represent the uncertainties of these empirical OLR diurnal models that can be attributed to several factors, including the magnitudes and the degrees of persistency of the re- 


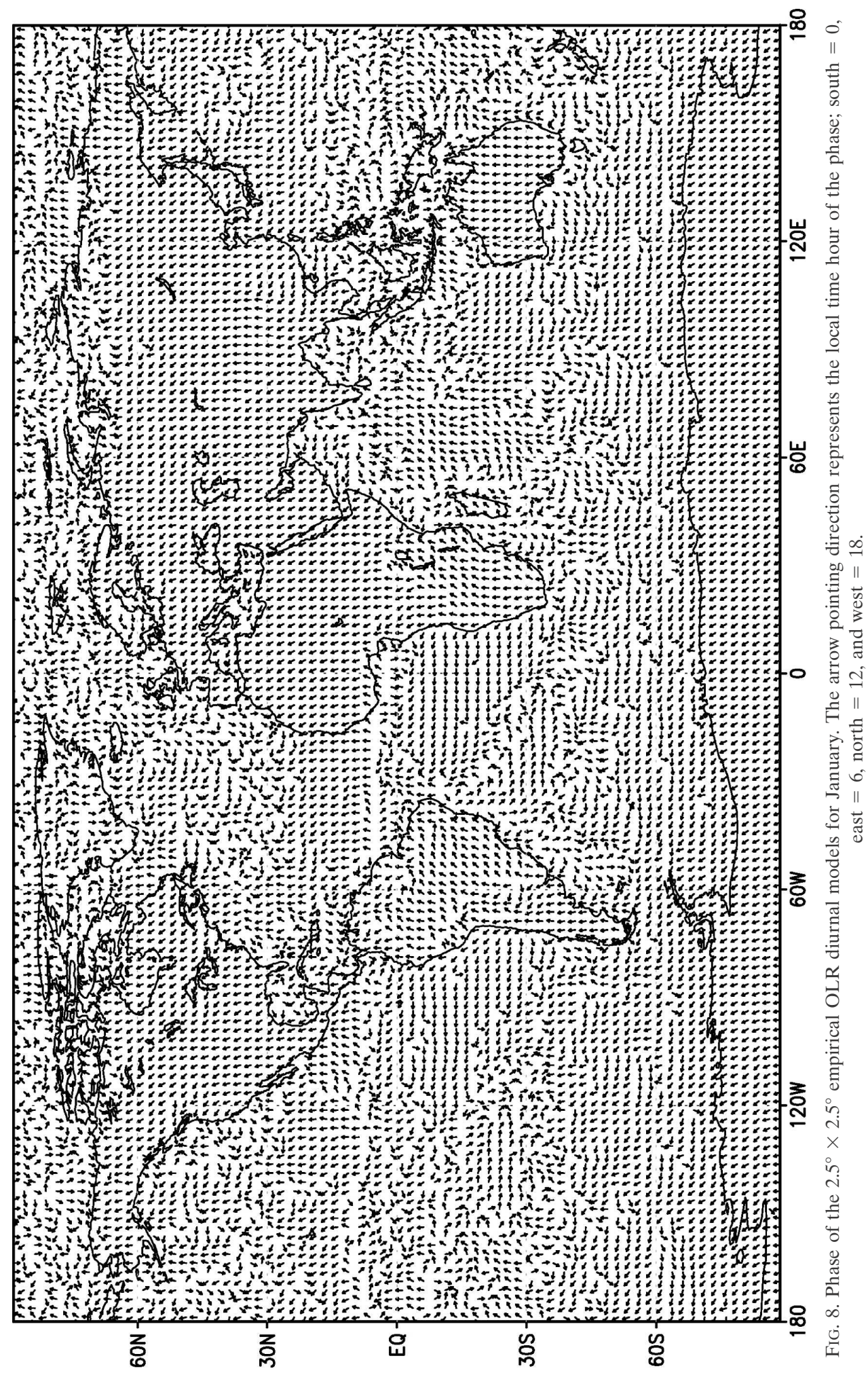




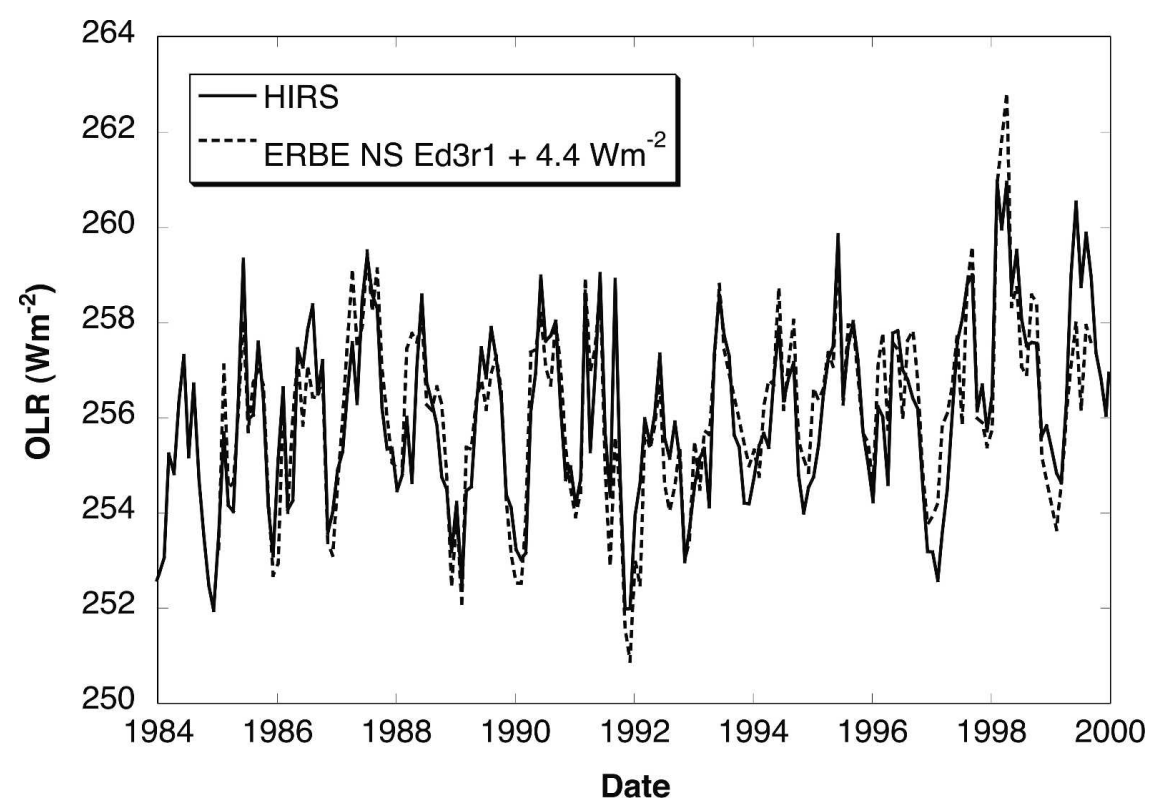

FIG. 9. Time series of the tropical $\left(20^{\circ} \mathrm{S}-20^{\circ} \mathrm{N}\right)$ mean OLR from ERBS nonscanner (dotted) and HIRS (solid). The ERBS nonscanner OLR has been offset by $+4.4 \mathrm{~W} \mathrm{~m}^{-2}$ for visual comparison purpose.

gional OLR diurnal variations, the interannual variations (as they are based on a 25-yr composite dataset), and the goodness of fit of the models.

Figure 8 shows the phase of the $2.5^{\circ} \times 2.5^{\circ}$ empirical OLR diurnal models. Preliminary analyses found that these results are consistent with those of Gruber and Chen (1988). The HIRS diurnal model also captured the near-midnight peaks over the Atlantic and the Gulf of Mexico and the near-noon peaks for North American deserts that were accurately determined with the GOES Sounder OLR data for July 1998 shown in Ellingson and $\mathrm{Ba}$ (2003). We also found that there are rather large variations both spatially and seasonally in the phase of the diurnal variation.

Comparing the HIRS OLR without and with the diurnal model for the monthly mean derivation, the discrepancies between the monthly mean OLR of HIRS and ERBE were significantly reduced by about $20 \%-$ $40 \%$ in RMS differences over most of the land. Note that the ERBE product was also subject to temporal sampling limitations and has assumed a half-sine diurnal model with a fixed noon phase over land. The most accurate estimate for the daily mean OLR could be obtained by a broadband instrument on board a geostationary satellite, for example, the Geostationary Earth Radiation Budget (GERB; Harries et al. 2005), or with the diurnal information from the geostationary satellite observations (Lee et al. 2004b; Young et al. 1998). Though without an accurate diurnally integrated
OLR product to validate with, this result was nevertheless encouraging and it indicated potential improvement in the HIRS OLR time series with the use of the diurnal model.

The impact of the diurnal model on the OLR differences between HIRS and CERES are smaller because higher temporal sampling was available with the coexisting two to four POES satellites during the period after 1998 (see Fig. 2).

The diurnal model determined from the 25-yr HIRS OLR retrievals provides a very consistent and complete description for the global OLR diurnal variations. It alleviates the temporal sampling problems associated with the orbital drift and with the observation availability. It ultimately improved the uniformity of the HIRS OLR time series.

\section{Intercomparison of OLR products}

We have intercompared several OLR products for quality control and validation purposes. Results shown here are focused on the HIRS and AVHRR in terms of their compatibility for climate-monitoring purposes using broadband OLR measurements from ERBE and CERES as references. More results will be reported in follow-up papers.

The broadband OLR products used here are the ERBS nonscanner, ERBE scanner, and CERES ERBE-like regional monthly mean datasets. The 
(a)

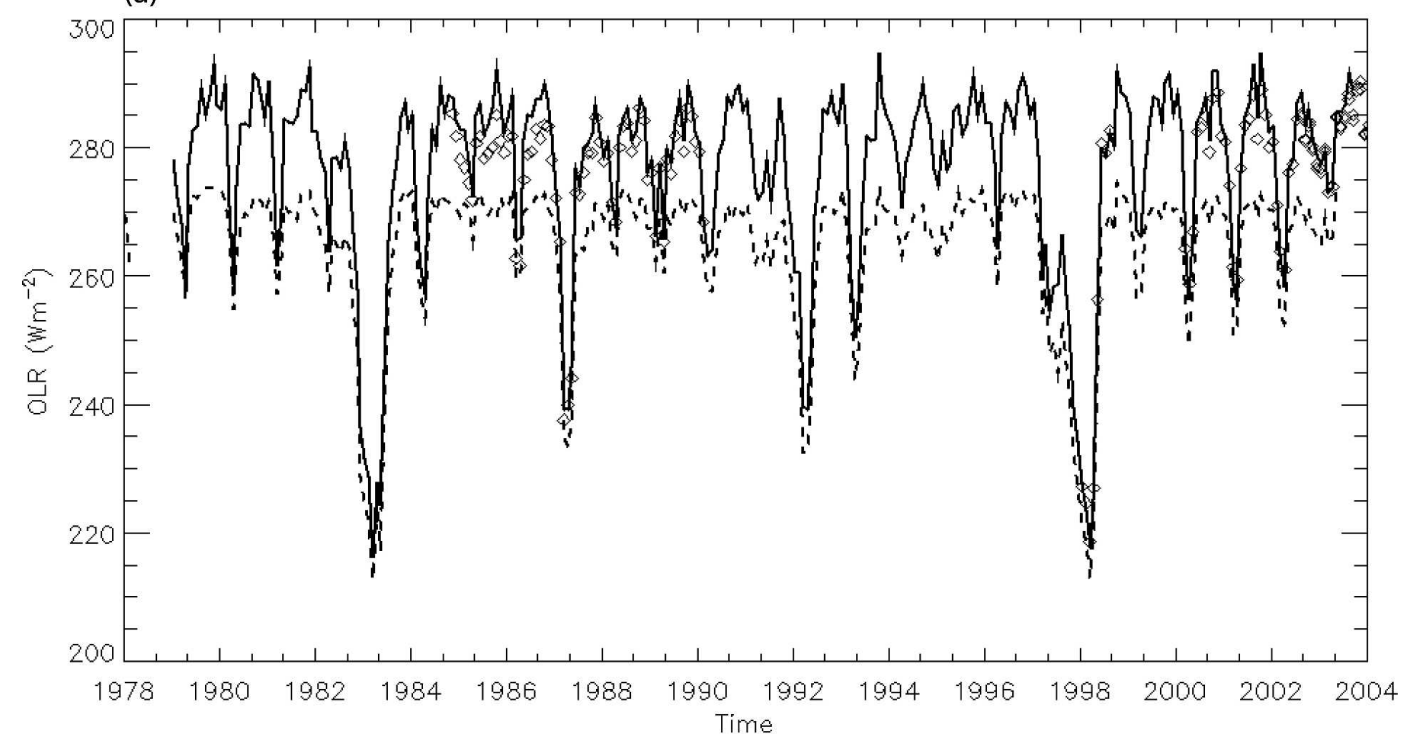

(b)

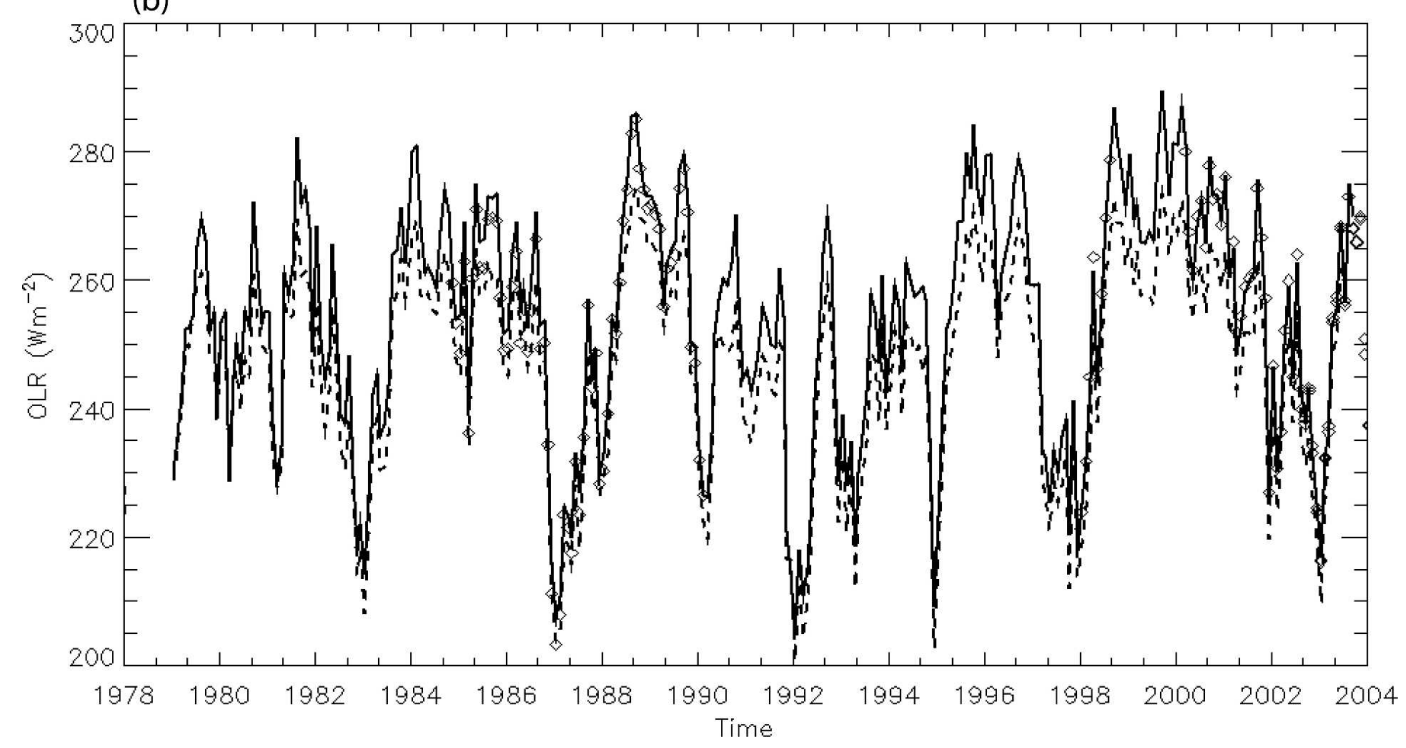

FIG. 10. Time series of the regional average OLR for (a) ENSO3 $\left(5^{\circ} \mathrm{S}-5^{\circ} \mathrm{N}, 150^{\circ}-90^{\circ} \mathrm{W}\right)$ and (b) ENSO4 $\left(5^{\circ} \mathrm{S}-5^{\circ} \mathrm{N}, 160^{\circ} \mathrm{E}-150^{\circ} \mathrm{W}\right)$ areas from HIRS (solid) and AVHRR (dashed) overlaid with the broadband observations by ERBE and CERES (diamond symbol).

ERBS nonscanner data (1985-99) used here is the Ed. 3 Rev. 1, which included the satellite height correction and the shortwave drift adjustment (Wong et al. 2006). The ERBE S4 dataset (1985-89) was derived from ERBE scanner instruments on board ERBS, NOAA-9, and NOAA-10 satellites. The CERES ERBE-like ES4 datasets were derived from the CERES scanner instruments on board the NASA Tropical Rainfall Measuring Mission (TRMM) (January-August 1998, Ed.2), and the EOS Terra (since March 2000, Ed.2) and Aqua (since July 2002, Ed.1) satellites. The AVHRR OLR dataset is the NESDIS operational product (Ohring et al. 1984) compiled by the NCEP Climate Prediction Center. It is similar to that of the AVHRR Pathfinder Climate dataset (PATMOS; Jacobowitz et al. 2003).

Figure 9 shows the time series (1985-99) of the tropical $\left(20^{\circ} \mathrm{S}-20^{\circ} \mathrm{N}\right)$ mean OLR from ERBS nonscanner and HIRS. The ERBS nonscanner is considered one of the most stable earth radiation budget instruments. Wong et al. (2006) found that the stability of the ERBS nonscanner OLR record is approximately $0.3 \mathrm{~W} \mathrm{~m}^{-2}$ 
(a)

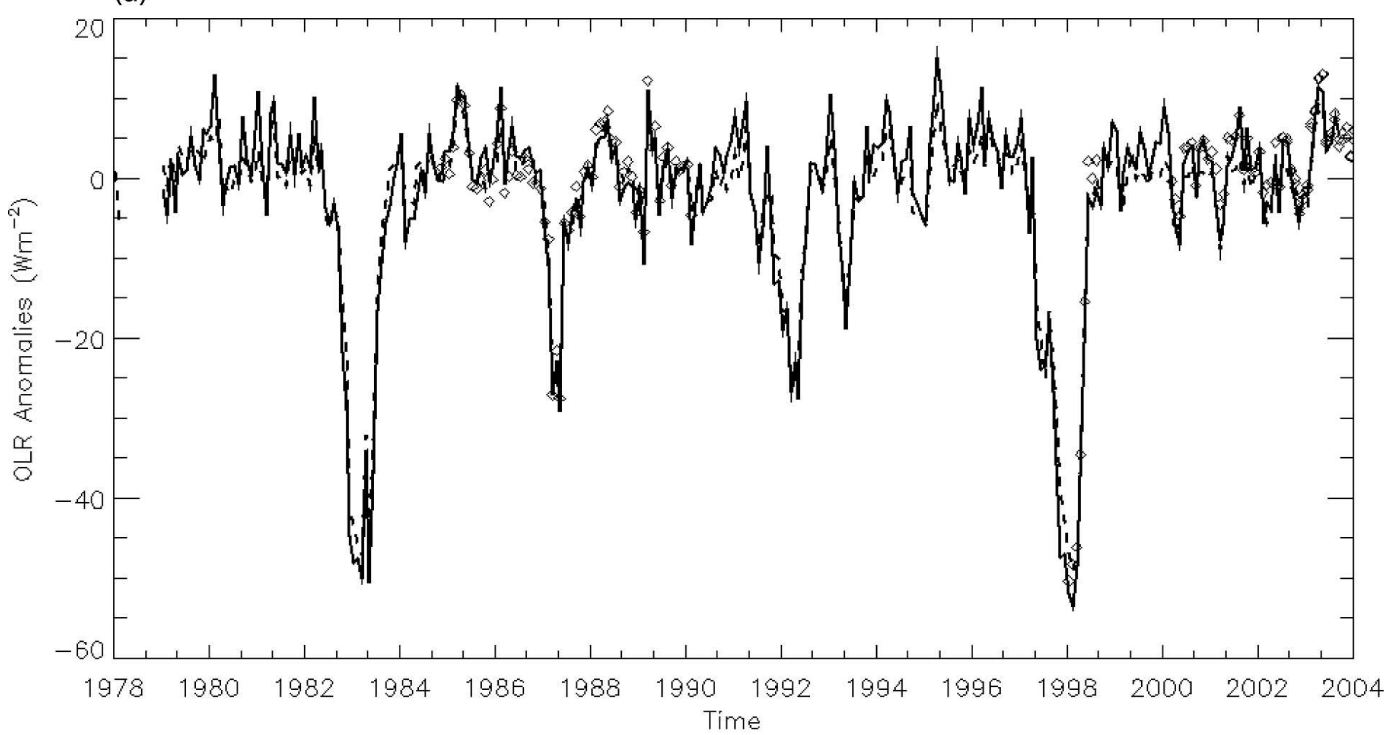

(b)

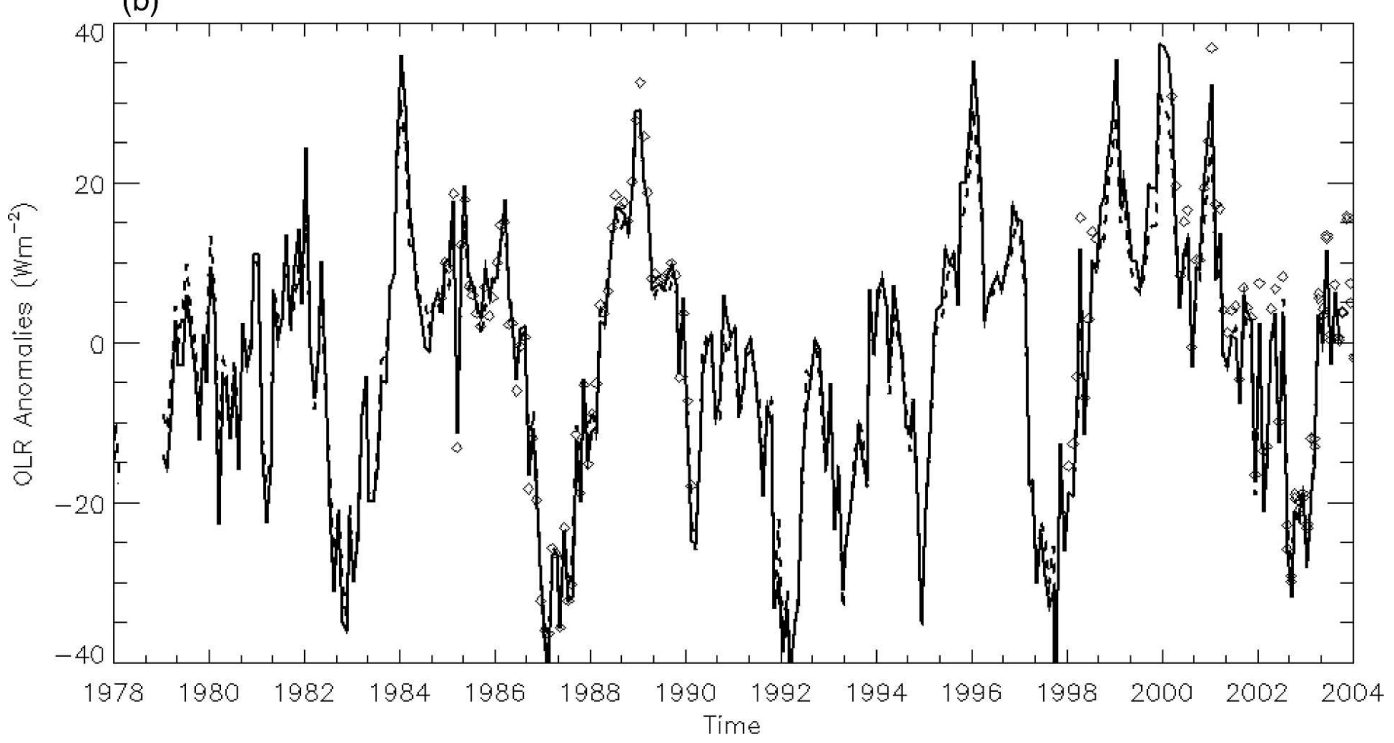

FIG. 11. Similar to Fig. 10, but for OLR anomalies with a common base period 1985-89.

decade $^{-1}$. The slope for the differences between the deseasonalized HIRS and ERBS nonscanner OLR anomalies (using the 1985-89 base period) is $0.088 \mathrm{~W}$ $\mathrm{m}^{-2}$ decade $^{-1}$ with a $95 \%$ confidence interval of $0.31 \mathrm{~W}$ $\mathrm{m}^{-2}$ decade $^{-1}$. The standard deviation of differences between ERBS nonscanner and HIRS tropical mean OLR is about $1 \mathrm{~W} \mathrm{~m}^{-2}$ with a best-fit line slope of about 0.998 , suggesting an essentially one-to-one relationship. The systematic difference between the HIRS and ERBS nonscanner tropical mean is about $4.4 \mathrm{~W}$ $\mathrm{m}^{-2}$. This is within the estimated absolute radiometry accuracy at about $2 \%$ for the ERBE instruments. The extraordinary agreement between the HIRS and ERBS nonscanner OLR time series for the 15 -yr period indi- cated that the HIRS has a stability that is comparable to the ERBS nonscanner.

Figure 10 shows time series of the regional average OLR for ENSO3 $\left(5^{\circ} \mathrm{S}-5^{\circ} \mathrm{N}, 150^{\circ}-90^{\circ} \mathrm{W}\right)$ and ENSO 4 $\left(5^{\circ} \mathrm{S}-5^{\circ} \mathrm{N}, 160^{\circ} \mathrm{E}-150^{\circ} \mathrm{W}\right)$ areas from HIRS and AVHRR overlaid with the broadband observations by ERBE and CERES. One can immediately notice that the HIRS has a superb agreement with the broadband observations for both of these ENSO-monitoring regions. AVHRR, however, seems to agree with the broadband observations better in the ENSO4 region than in ENSO3. It was recognized that the AVHRR OLR algorithm is relatively insensitive to water vapor variations and atmospheric variations, such as tempera- 

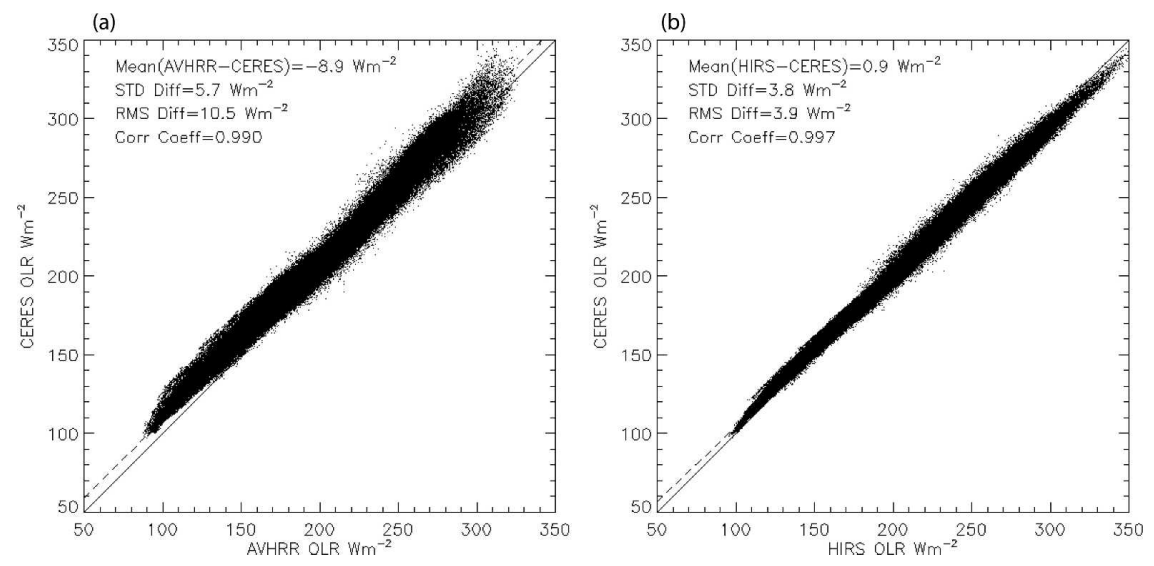

FIG. 12. Scatterplot of the monthly mean OLR data for the common period March 2000-June 2003 for (a) CERES vs AVHRR and (b) CERES vs HIRS.

ture inversion, that can lead to large biases (Gruber et al. 1994). These problems could lead to inaccurate retrievals in certain regions, particularly in the form of biases (see Fig. 13a). The ENSO3 region is located near the end of cold tongue in the eastern Pacific Ocean where climatologically it is less cloudy except during El Niño years, while climatologically the ENSO4 region has higher cloud cover [e.g., International Satellite Cloud Climatology Project (ISCCP) D2 cloud cover climatology available online at http://isccp.giss.nasa.gov/ products/browsed2.html]. The AVHRR depicts the OLR variations quite well when they were primarily induced by the cloud variations, for example, ENSO4 and El Niño years in ENSO3. However, rather persistent large biases in AVHRR OLR can be found for the ENSO3 region, consistently with the past studies, which confirmed the "inability of window channel algorithm to predict the correct average flux for certain persistent climatological structures" (Gruber et al. 1994).

Figure 11 shows the time series of the deseasonalized anomalies of the regional average OLR corresponding to those in Fig. 10. The OLR anomalies were calculated using the common 1985-89 base periods for all datasets. The anomalies of HIRS OLR again agree closely with the broadband data as expected. But it was surprising to find that the AVHRR OLR anomalies show very good agreement with both HIRS and the broadband results in the ENSO3 region. This suggests that the AVHRR OLR might have persistent biases that are regionally and/or seasonally dependent such that those biases were removed in the deseasonalized anomaly fields.

Figure 12 presents the scatterplots of the monthly mean OLR among AVHRR, HIRS, and CERES. The CERES data used here are limited to those from the Terra platform. The overlapping period for all three datasets is March 2000 to June 2003. The area-weighted global mean OLR differences of AVHRR minus CERES is about $-9 \mathrm{~W} \mathrm{~m}^{-2}$, with a standard deviation of about $8 \mathrm{~W} \mathrm{~m}^{-2}$. The RMS OLR differences between AVHRR and CERES is near $12 \mathrm{~W} \mathrm{~m}^{-2}$. Their correlation coefficient is high however: 0.990. The mean OLR differences of HIRS minus CERES is about $2 \mathrm{~W}$ $\mathrm{m}^{-2}$ with a standard deviation of about $4 \mathrm{~W} \mathrm{~m}^{-2}$. The RMS OLR differences between HIRS and CERES is about $5 \mathrm{~W} \mathrm{~m}^{-2}$, less than half of that of AVHRR. The correlation between HIRS and CERES is a little higher at 0.997 . Table 3 summaries these statistics.

Figure 13 shows the contour plots of the averaged monthly mean OLR differences for the period March 2000-June 2003 for AVHRR minus CERES, and HIRS minus CERES. The contour levels for AVHRR and HIRS plots are different in order to compare the regional features on top of the overall biases. The two contour maps share some similarities, including the negative biases over the cold elevated regions (e.g., Antarctica and Greenland), positive biases over the desert (e.g., North Africa). For those biases near the eastern Pacific cold tongue and other subtropical high regions, the AVHRR and HIRS seem to behave oppositely. Gruber et al. (1994) explained that the negative biases in AVHRR OLR over subtropical oceans were related to the trade wind inversion and the positive biases over desert regions were related to the strong

TABLE 3. Area-weighted statistics for the global $2.5^{\circ} \times 2.5^{\circ}$ monthly mean OLR products between AVHRR, HIRS, and CERES for March 2000-June 2003.

\begin{tabular}{|c|c|c|c|c|}
\hline & $\begin{array}{l}\text { Mean diff } \\
\left(\mathrm{W} \mathrm{m}^{-2}\right)\end{array}$ & $\begin{array}{c}\text { Std dev } \\
\text { of diff } \\
\left(\mathrm{W} \mathrm{m} \mathrm{m}^{-2}\right)\end{array}$ & $\begin{array}{l}\text { RMS diff } \\
\left(\mathrm{W} \mathrm{m}^{-2}\right)\end{array}$ & Correlation \\
\hline AVHRR-CERES & -8.5 & 7.7 & 11.5 & 0.990 \\
\hline HIRS-CERES & 1.5 & 4.3 & 4.6 & 0.997 \\
\hline
\end{tabular}


(a)

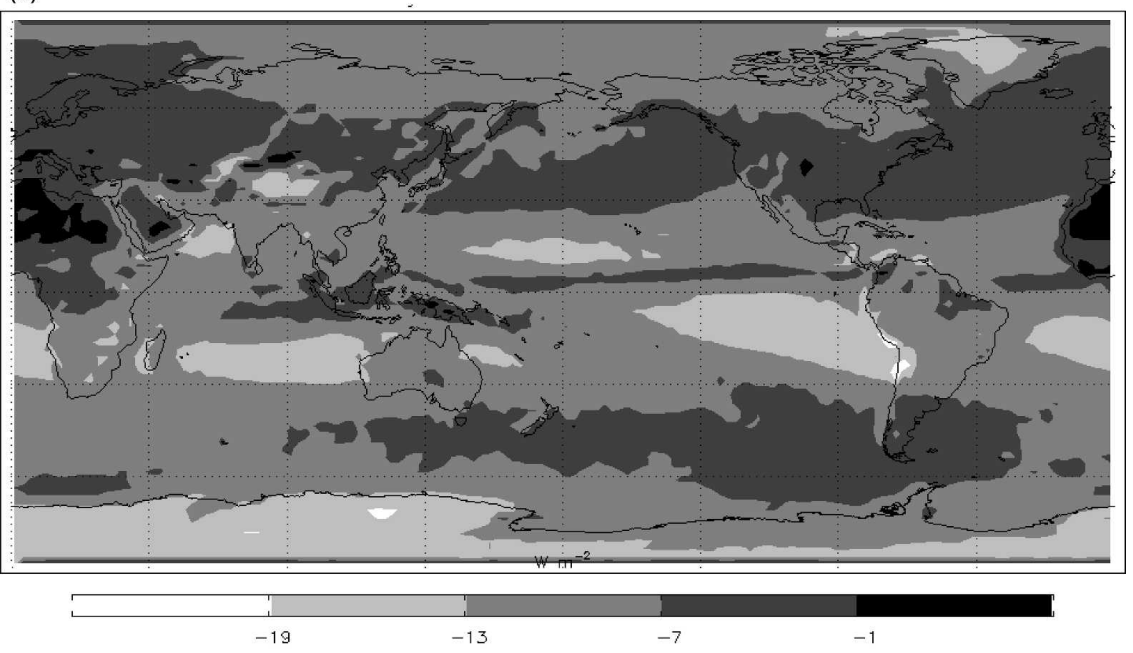

(b)

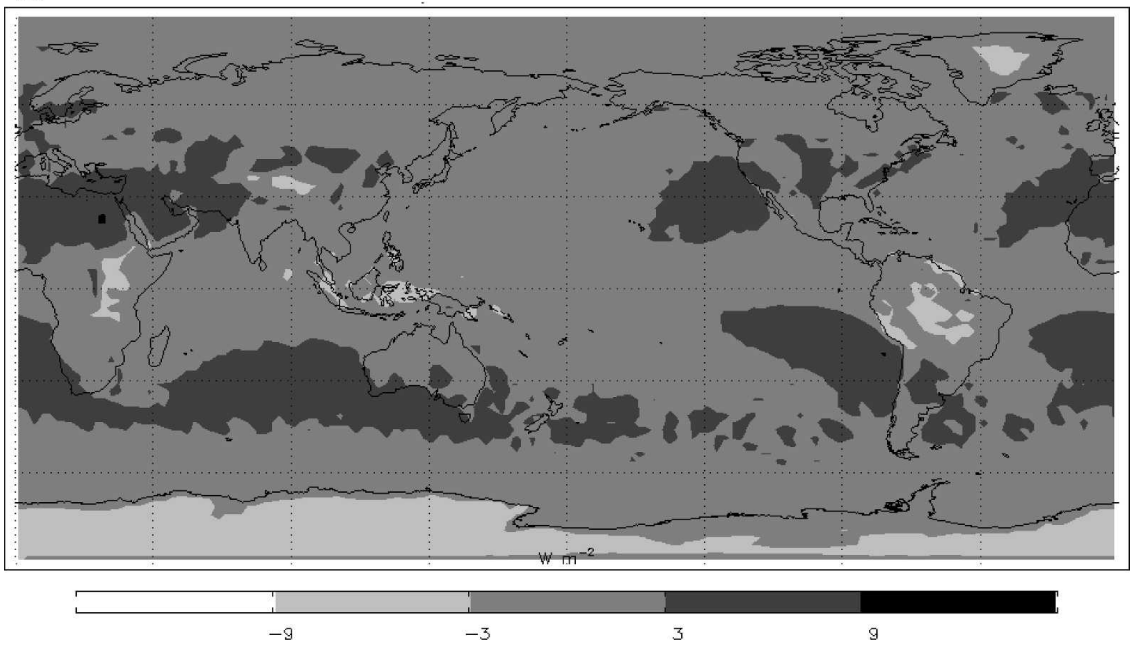

FIG. 13. Contour plots of the averaged monthly mean OLR differences for the period March 2000-June 2003 for (a) AVHRR minus CERES and (b) HIRS minus CERES. Note the differences in the contour levels.

skin/surface temperature discontinuity. Our preliminary analysis suggested that the difference between HIRS and CERES in this region might be related to the diurnal variations that CERES ERBE-like data did not use any diurnal model over the oceans while HIRS was derived with the empirical OLR diurnal models. HIRS has a similar but milder overestimating problem over the deserts. This might be related to the lowertropospheric temperature channel used in the HIRS OLR algorithm for the HIRS/3 and HIRS/4 instruments that were oversensitive to the skin temperature. Low biases over Antarctica and Greenland were shown in both datasets. We suspect that those biases related to the radiation simulation during algorithm development where the dry, cold, and elevated conditions were not well represented. We will continue the study to confirm and identify the sources of these errors, including the positive bias in HIRS OLR over the subtropical oceans. Overall, the averaged differences between HIRS and CERES monthly mean OLR are within $3 \mathrm{~W} \mathrm{~m}^{-2}$ in most regions.

Figure 14 shows the standard deviation of the monthly mean OLR differences corresponding to those in Fig. 13. It shows that the HIRS OLR's precision relative to the CERES is within about $3 \mathrm{~W} \mathrm{~m}^{-2}$ in most of the globe except the tropical land areas where the differences in diurnal modeling in the two datasets might partly account for. It is quite apparent that, relative to CERES, the AVHRR OLR's precision is much lower than that of HIRS, with particularly large uncertainties in the deserts (e.g., Africa, southwest Asia, and Australia) and elevated regions (e.g., the Rockies and 
(a)

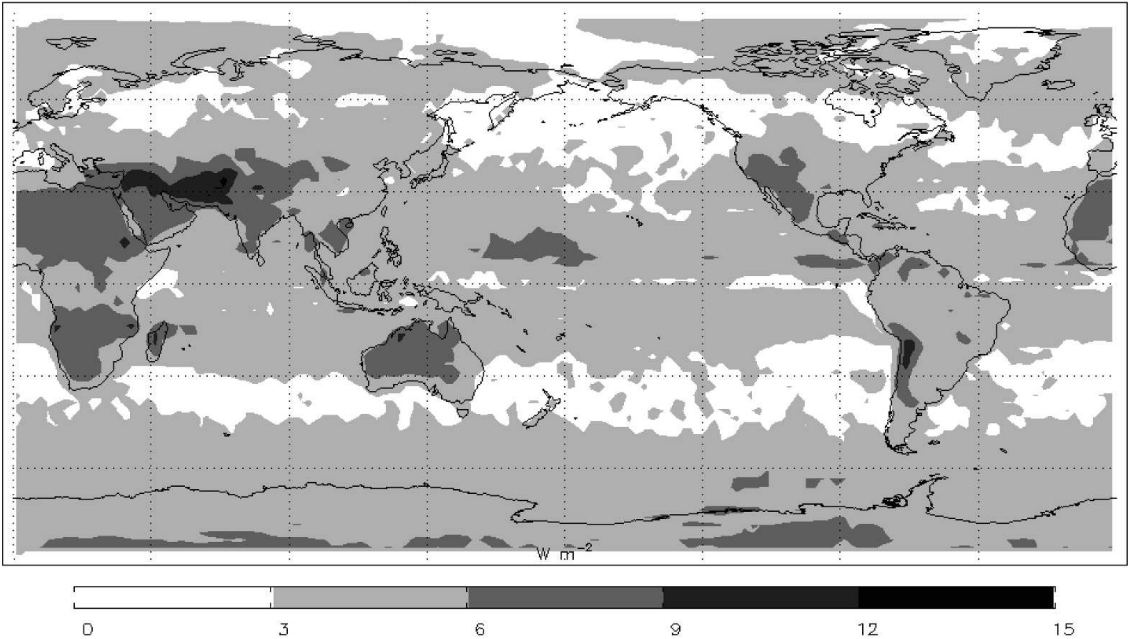

(b)

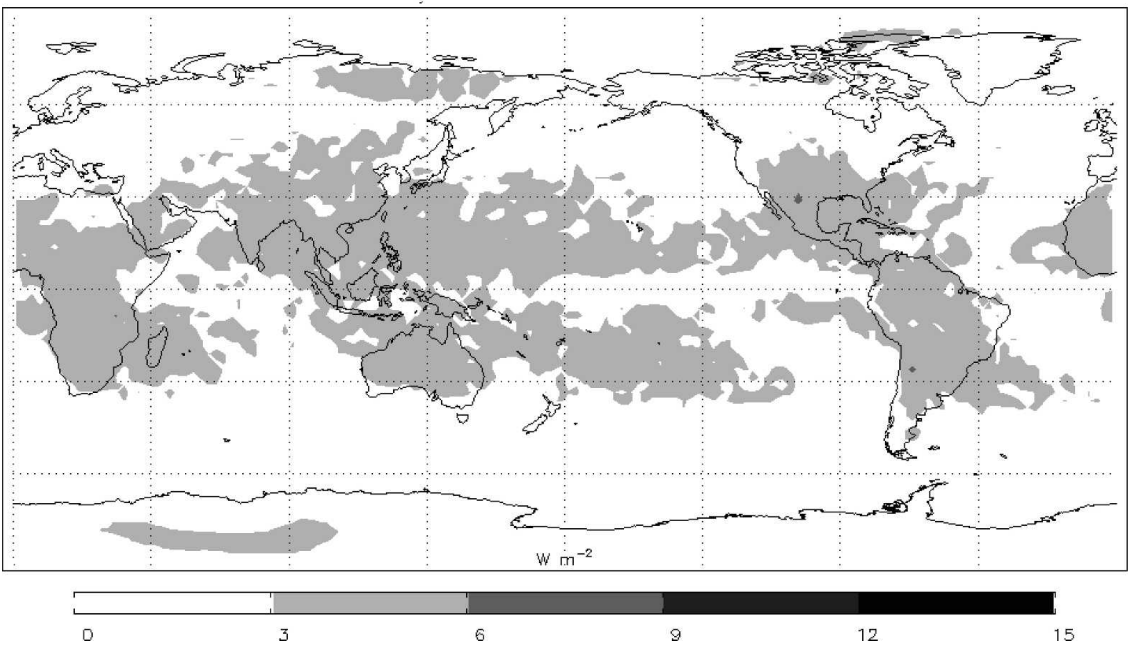

FIG. 14. Similar to Fig. 13, but the standard deviation for (a) AVHRR minus CERES and

(b) HIRS minus CERES.

the Andes). Figure 15 shows the time series of the global average of the monthly mean OLR. The mean differences of 1.5 and $-8.5 \mathrm{~W} \mathrm{~m}^{-2}$ relative to CERES were removed for visual comparison purposes, for HIRS and AVHRR, respectively. The three datasets have all depicted annual cycles with identical phases and similar amplitudes. Overall, HIRS agrees with CERES to within about $2 \mathrm{~W} \mathrm{~m}^{-2}$. The AVHRR, other than the biases, seems to also have a slight upward trend that was probably related to the uncorrected orbital drift effects in the AVHRR dataset.

\section{Summary}

This paper describes the generation of the new HIRS OLR climate dataset. The HIRS level $1 b$ data from the entire TIROS-N satellites have been assembled for the reprocessing of the HIRS OLR product. A new radi- ance calibration procedure was applied to obtain more accurate and consistent HIRS radiance measurements. The regression coefficients of the HIRS OLR algorithm for all satellites were rederived from calculations of an improved radiative transfer model. Intersatellite calibrations were performed to remove possible discontinuity in the HIRS OLR products from different satellites. A set of global monthly diurnal models was constructed consistent with the HIRS OLR retrievals.

The use of empirical diurnal models largely reduced the temporal sampling errors in the monthly mean OLR estimates and alleviated the orbital-drift-induced artificial trends; it significantly improved the accuracy, continuity, and uniformity of the HIRS monthly mean OLR time series. It is shown that the HIRS OLR time series has a comparable stability as the ERBS nonscanner measurements. 


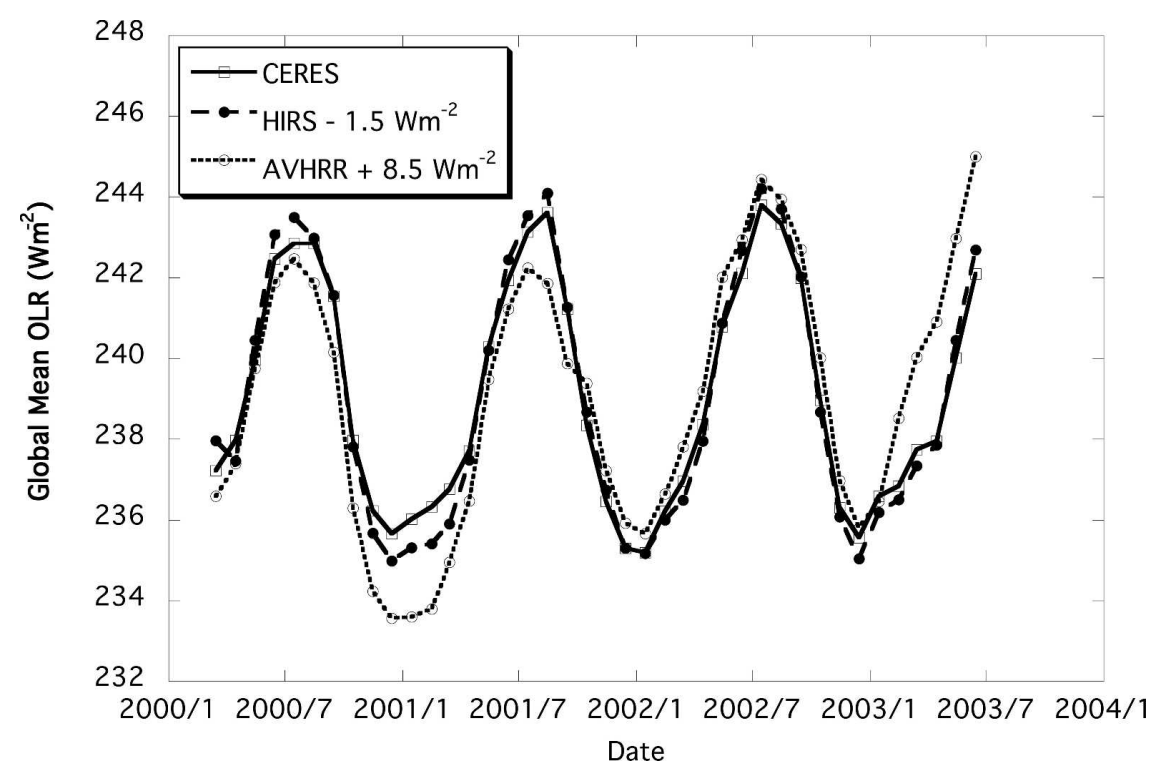

FIG. 15. Time series of the global average of the monthly mean OLR of CERES (solid), HIRS (dashed), and AVHRR (dotted). The mean differences of 1.5 and $-8.5 \mathrm{~W} \mathrm{~m}^{-2}$ relative to CERES were removed for visual comparison purpose, for HIRS and AVHRR, respectively.

HIRS OLR has superb agreement with the broadband observations in the ENSO monitoring regions. Globally, HIRS OLR agrees with CERES with an accuracy of within $2 \mathrm{~W} \mathrm{~m}^{-2}$ and a precision of about $5 \mathrm{~W}$ $\mathrm{m}^{-2}$. The correlation coefficient between HIRS and CERES global monthly mean is 0.997 . Regionally, HIRS OLR agrees with CERES to within $3 \mathrm{~W} \mathrm{~m}^{-2}$ with a precision better than $3 \mathrm{~W} \mathrm{~m}^{-2}$ in most places.

AVHRR and HIRS OLR have compatible ENSOmonitoring capability. Their OLR anomaly time series agree closely over the ENSO3 and ENSO4 regions. Nevertheless, the AVHRR OLR seems to have an overall negative bias of $9 \mathrm{~W} \mathrm{~m}^{-2}$ with respect to the CERES with a precision of about $8 \mathrm{~W} \mathrm{~m}^{-2}$. Regionally, the precisions of the AVHRR OLR are mostly within $6 \mathrm{~W} \mathrm{~m}^{-2}$.

The HIRS OLR dataset from the entire NOAA TIROS-N satellites constitutes a new OLR climate data record. It could be used for constructing the climatology for applications that plan to use NPOESS ERBS observations but were previously using AVHRR OLR. The HIRS monthly mean OLR data showed a high accuracy and precision with respect to the broadband observations of CERES. It can be used as an independent validation data source. The uniformity and continuity of the HIRS OLR time series suggest that it could be a reliable transfer reference for the discontinuous broadband measurements. More detailed time series analyses between the HIRS, ERBE/CERES and other OLR products will be presented in follow-up papers.

The HIRS OLR climate data record is currently available at the CICS Web site http://cics.umd.edu/ HIRS_OLR. Besides the datasets, information regarding the algorithm, coefficients, data format, and revision history of the datasets will also be maintained at the site and is also available upon request from the authors.

Acknowledgments. This study was supported by the triagency Integrated Program Office NPOESS Risk Reduction Project through CICS Grant NA17EC1483. The authors would like to thank Larry McMillin for providing initial HIRS level $1 \mathrm{~b}$ data and helpful discussions about the reconstruction of local zenith angles. We would also like to thank Larry McMillin and Jiang Zhao for providing the software and temperature correction coefficients for the radiance calibration procedure. We want to express our thanks to Darren Jackson and John Bates at the NOAA/Environmental Technology Laboratory for providing complementary HIRS level $1 \mathrm{~b}$ data and HIRS clear-sky radiances. We also thank Axel Graumann at the NOAA/National Climatic Data Center for providing the complete HIRS level $1 \mathrm{~b}$ datasets through CLASS. We also thank the NASA Langley Atmospheric Science Data Center for providing the ERBE and CERES datasets. We also express our appreciation to Takmeng Wong and Shi-Keng Yang for their very helpful suggestions and discussions. Finally, we thank the three anonymous reviewers whose comments have greatly improved the clarity of this paper. 


\section{APPENDIX}

\section{HIRS OLR Regression Coefficients for NOAA TIROS-N Satellites}

Tables A1-A13 contain HIRS OLR regression coefficients for NOAA TIROS-N satellites. Column legends are VZA $=$ local viewing zenith angle $\left({ }^{\circ}\right)$, regression coefficient $a_{0}\left(\mathrm{~W} \mathrm{~m}^{-2}\right)$, and regression coefficients $a_{i}\left(\mathrm{~cm}^{-1} \mathrm{sr}\right), i=1,4$.

TABLE A1. TIROS-N.

\begin{tabular}{rccccc}
\hline \hline VZA & $a_{0}$ & $a_{1}$ & $a_{2}$ & $a_{3}$ & $a_{4}$ \\
\hline 0 & 30.04 & 401.641 & 1440.27 & 957.519 & 7010.32 \\
5 & 30.18 & 401.015 & 1437.4 & 964.943 & 7004.94 \\
10 & 30.64 & 399.140 & 1428.1 & 987.781 & 6989.60 \\
15 & 31.43 & 395.963 & 1412.82 & 1026.49 & 6962.02 \\
20 & 32.59 & 391.424 & 1389.94 & 1082.49 & 6920.58 \\
25 & 34.18 & 385.536 & 1358.37 & 1157.66 & 6862.52 \\
30 & 36.32 & 378.104 & 1316.11 & 1254.85 & 6783.76 \\
35 & 39.11 & 369.174 & 1260.65 & 1377.57 & 6677.96 \\
40 & 42.76 & 358.528 & 1187.89 & 1531.00 & 6539.93 \\
45 & 47.49 & 346.354 & 1092.74 & 1721.36 & 6360.77 \\
50 & 53.68 & 332.669 & 967.345 & 1957.26 & 6132.94 \\
55 & 61.77 & 318.105 & 801.313 & 2248.66 & 5852.23 \\
60 & 72.32 & 304.040 & 581.864 & 2604.99 & 5523.84 \\
65 & 85.84 & 293.504 & 297.419 & 3027.50 & 5179.08 \\
\hline
\end{tabular}

TABLE A2. NOAA-6.

\begin{tabular}{rccccc}
\hline \hline VZA & $a_{0}$ & $a_{1}$ & $a_{2}$ & $a_{3}$ & $a_{4}$ \\
\hline 0 & 31.07 & 396.935 & 1415.49 & 984.190 & 6925.53 \\
5 & 31.23 & 396.330 & 1412.47 & 991.933 & 6920.03 \\
10 & 31.70 & 394.511 & 1402.94 & 1015.71 & 6904.11 \\
15 & 32.51 & 391.426 & 1386.67 & 1056.05 & 6875.75 \\
20 & 33.70 & 387.028 & 1362.69 & 1114.41 & 6833.28 \\
25 & 35.35 & 381.323 & 1329.62 & 1192.80 & 6773.78 \\
30 & 37.54 & 374.133 & 1285.47 & 1294.15 & 6693.13 \\
35 & 40.41 & 365.498 & 1227.64 & 1422.17 & 6585.03 \\
40 & 44.15 & 355.237 & 1151.91 & 1582.38 & 6444.12 \\
45 & 48.99 & 343.543 & 1053.12 & 1781.26 & 6261.34 \\
50 & 55.30 & 330.475 & 923.264 & 2027.98 & 6028.67 \\
55 & 63.54 & 316.721 & 751.615 & 2333.27 & 5741.65 \\
60 & 74.26 & 303.788 & 525.008 & 2707.50 & 5404.95 \\
65 & 87.98 & 294.918 & 231.085 & 3153.05 & 5050.74 \\
\hline
\end{tabular}

TABle A3. NOAA-7.

\begin{tabular}{rccccc}
\hline \hline VZA & $a_{0}$ & $a_{1}$ & $a_{2}$ & $a_{3}$ & $a_{4}$ \\
\hline 0 & 27.70 & 410.464 & 1495.10 & 862.270 & 7082.56 \\
5 & 27.85 & 409.834 & 1492.16 & 869.867 & 7077.30 \\
10 & 28.31 & 407.949 & 1482.94 & 893.118 & 7061.73 \\
15 & 29.11 & 404.758 & 1467.13 & 932.632 & 7034.20 \\
20 & 30.29 & 400.196 & 1443.82 & 989.794 & 6992.72 \\
25 & 31.92 & 394.292 & 1411.50 & 1066.70 & 6934.71 \\
30 & 34.10 & 386.842 & 1368.13 & 1166.29 & 6856.24 \\
35 & 36.96 & 377.878 & 1311.04 & 1292.31 & 6751.21 \\
40 & 40.70 & 367.188 & 1235.87 & 1450.28 & 6614.61 \\
45 & 45.58 & 354.964 & 1137.14 & 1646.93 & 6438.48 \\
\hline
\end{tabular}

TABle A3. (Continued)

\begin{tabular}{cccccc}
\hline \hline VZA & $a_{0}$ & $a_{1}$ & $a_{2}$ & $a_{3}$ & $a_{4}$ \\
\hline 50 & 51.97 & 341.116 & 1006.62 & 1891.42 & 6215.87 \\
55 & 60.35 & 326.211 & 833.250 & 2194.70 & 5943.69 \\
60 & 71.31 & 311.407 & 603.434 & 2567.39 & 5628.37 \\
65 & 85.42 & 299.323 & 304.555 & 3012.52 & 5300.66
\end{tabular}

TABle A4. NOAA-8.

\begin{tabular}{rccccc}
\hline VZA & $a_{0}$ & $a_{1}$ & $a_{2}$ & $a_{3}$ & $a_{4}$ \\
\hline 0 & 30.58 & 397.108 & 1427.92 & 983.827 & 7061.65 \\
5 & 30.73 & 396.484 & 1425.09 & 991.170 & 7056.43 \\
10 & 31.18 & 394.606 & 1416.18 & 1013.66 & 7041.15 \\
15 & 31.96 & 391.423 & 1400.99 & 1051.79 & 7013.88 \\
20 & 33.10 & 386.881 & 1378.59 & 1106.90 & 6972.82 \\
25 & 34.68 & 380.990 & 1347.65 & 1180.88 & 6915.18 \\
30 & 36.78 & 373.562 & 1306.30 & 1276.45 & 6836.79 \\
35 & 39.54 & 364.630 & 1252.09 & 1396.99 & 6731.33 \\
40 & 43.13 & 354.007 & 1180.98 & 1547.58 & 6593.43 \\
45 & 47.80 & 341.872 & 1088.03 & 1734.23 & 6414.04 \\
50 & 53.88 & 328.269 & 965.656 & 1965.20 & 6185.15 \\
55 & 61.83 & 313.866 & 803.724 & 2250.10 & 5901.76 \\
60 & 72.20 & 300.094 & 589.760 & 2597.89 & 5568.21 \\
65 & 85.48 & 290.063 & 312.543 & 3009.39 & 5214.08 \\
\hline
\end{tabular}

TABLE A5. NOAA-9.

\begin{tabular}{rccccc}
\hline \hline VZA & $a_{0}$ & $a_{1}$ & $a_{2}$ & $a_{3}$ & $a_{4}$ \\
\hline 0 & 28.68 & 406.188 & 1472.50 & 882.857 & 7051.12 \\
5 & 28.83 & 405.560 & 1469.68 & 890.198 & 7045.84 \\
10 & 29.28 & 403.685 & 1460.77 & 912.745 & 7030.34 \\
15 & 30.06 & 400.506 & 1445.53 & 951.004 & 7002.81 \\
20 & 31.22 & 395.964 & 1423.02 & 1006.37 & 6961.40 \\
25 & 32.81 & 390.071 & 1391.86 & 1080.78 & 6903.42 \\
30 & 34.94 & 382.639 & 1350.02 & 1177.12 & 6824.96 \\
35 & 37.74 & 373.693 & 1294.95 & 1298.93 & 6719.87 \\
40 & 41.40 & 363.022 & 1222.40 & 1451.53 & 6583.06 \\
45 & 46.17 & 350.797 & 1127.11 & 1641.31 & 6406.35 \\
50 & 52.43 & 336.973 & 1001.02 & 1877.10 & 6182.53 \\
55 & 60.64 & 322.105 & 833.332 & 2169.36 & 5908.13 \\
60 & 71.39 & 307.438 & 610.590 & 2528.31 & 5589.40 \\
65 & 85.23 & 295.722 & 320.125 & 2956.76 & 5257.40 \\
\hline
\end{tabular}

TABLE A6. NOAA-10.

\begin{tabular}{rccccc}
\hline \hline VZA & $a_{0}$ & $a_{1}$ & $a_{2}$ & $a_{3}$ & $a_{4}$ \\
\hline 0 & 26.55 & 406.965 & 1531.94 & 793.429 & 6986.95 \\
5 & 26.71 & 406.351 & 1528.71 & 801.633 & 6981.41 \\
10 & 27.21 & 404.522 & 1518.55 & 826.785 & 6965.19 \\
15 & 28.06 & 401.423 & 1501.13 & 869.552 & 6936.56 \\
20 & 29.32 & 396.997 & 1475.42 & 931.512 & 6893.72 \\
25 & 31.05 & 391.278 & 1439.83 & 1014.98 & 6833.97 \\
30 & 33.38 & 384.067 & 1392.12 & 1123.25 & 6753.53 \\
35 & 36.42 & 375.406 & 1329.35 & 1260.56 & 6646.63 \\
40 & 40.41 & 365.095 & 1246.86 & 1433.09 & 6508.33 \\
45 & 45.59 & 353.362 & 1138.66 & 1648.49 & 6331.32 \\
50 & 52.36 & 340.082 & 995.800 & 1917.31 & 6109.46 \\
55 & 61.25 & 325.854 & 806.226 & 2252.34 & 5841.03 \\
60 & 72.85 & 311.853 & 555.056 & 2666.62 & 5534.51 \\
65 & 87.77 & 300.709 & 227.915 & 3166.09 & 5224.36 \\
\hline
\end{tabular}


TABLE A7. NOAA-11.

\begin{tabular}{rccccc}
\hline \hline VZA & $a_{0}$ & $a_{1}$ & $a_{2}$ & $a_{3}$ & $a_{4}$ \\
\hline 0 & 46.89 & 344.139 & 1326.68 & 3206.54 & 1697.98 \\
5 & 46.82 & 343.726 & 1329.93 & 3188.27 & 1719.82 \\
10 & 46.63 & 342.361 & 1339.78 & 3131.84 & 1789.21 \\
15 & 46.30 & 340.086 & 1356.40 & 3036.05 & 1906.48 \\
20 & 45.84 & 336.850 & 1380.15 & 2896.91 & 2078.26 \\
25 & 45.25 & 332.380 & 1411.51 & 2709.77 & 2309.88 \\
30 & 44.53 & 326.672 & 1451.21 & 2466.79 & 2612.20 \\
35 & 43.68 & 319.559 & 1500.25 & 2157.86 & 2998.63 \\
40 & 42.69 & 310.834 & 1559.84 & 1769.17 & 3487.62 \\
45 & 41.60 & 299.887 & 1631.78 & 1280.05 & 4107.17 \\
50 & 40.39 & 286.847 & 1718.37 & 662.109 & 4892.96 \\
55 & 39.17 & 270.925 & 1822.47 & -127.635 & 5903.17 \\
60 & 38.11 & 252.196 & 1946.85 & -1147.02 & 7210.77 \\
65 & 37.75 & 231.496 & 2091.17 & -2466.96 & 8902.11 \\
\hline
\end{tabular}

TABLE A8. NOAA-12.

\begin{tabular}{rccccc}
\hline \hline VZA & $a_{0}$ & $a_{1}$ & $a_{2}$ & $a_{3}$ & $a_{4}$ \\
\hline 0 & 25.87 & 399.047 & 1565.11 & 674.700 & 6878.48 \\
5 & 26.03 & 398.462 & 1561.87 & 682.799 & 6873.00 \\
10 & 26.52 & 396.732 & 1551.70 & 707.625 & 6856.70 \\
15 & 27.38 & 393.786 & 1534.32 & 749.792 & 6827.86 \\
20 & 28.63 & 389.585 & 1508.64 & 810.951 & 6784.82 \\
25 & 30.37 & 384.159 & 1473.01 & 893.454 & 6724.95 \\
30 & 32.70 & 377.330 & 1425.15 & 1000.66 & 6644.92 \\
35 & 35.77 & 369.128 & 1362.07 & 1136.86 & 6538.74 \\
40 & 39.78 & 359.384 & 1278.93 & 1308.45 & 6402.25 \\
45 & 45.01 & 348.368 & 1169.55 & 1523.29 & 6228.81 \\
50 & 51.87 & 335.885 & 1024.50 & 1792.57 & 6013.28 \\
55 & 60.90 & 322.602 & 830.980 & 2130.00 & 5756.19 \\
60 & 72.75 & 309.725 & 572.677 & 2550.43 & 5469.47 \\
65 & 88.08 & 299.958 & 232.681 & 3063.01 & 5193.49 \\
\hline
\end{tabular}

TABLE A9. NOAA-14.

\begin{tabular}{rccccc}
\hline \hline VZA & $a_{0}$ & $a_{1}$ & $a_{2}$ & $a_{3}$ & $a_{4}$ \\
\hline 0 & 47.12 & 339.656 & 1325.86 & 3207.11 & 1738.51 \\
5 & 47.06 & 339.232 & 1329.10 & 3189.09 & 1760.14 \\
10 & 46.86 & 337.831 & 1338.91 & 3133.43 & 1828.82 \\
15 & 46.54 & 335.495 & 1355.49 & 3038.90 & 1944.98 \\
20 & 46.09 & 332.167 & 1379.16 & 2901.62 & 2115.05 \\
25 & 45.51 & 327.579 & 1410.42 & 2717.00 & 2344.35 \\
30 & 44.80 & 321.711 & 1450.00 & 2477.26 & 2643.71 \\
35 & 43.96 & 314.391 & 1498.89 & 2172.47 & 3026.21 \\
40 & 42.99 & 305.393 & 1558.29 & 1789.00 & 3510.17 \\
45 & 41.92 & 294.102 & 1630.00 & 1306.47 & 4123.23 \\
50 & 40.75 & 280.609 & 1716.31 & 696.905 & 4900.49 \\
55 & 39.57 & 264.095 & 1820.06 & -82.0577 & 5899.30 \\
60 & 38.56 & 244.564 & 1943.99 & -1087.26 & 7191.11 \\
65 & 38.28 & 222.786 & 2087.70 & -2388.21 & 8859.79 \\
\hline
\end{tabular}

TABLE A10. NOAA-15.

\begin{tabular}{rccccc}
\hline \hline VZA & $a_{0}$ & $a_{1}$ & $a_{2}$ & $a_{3}$ & $a_{4}$ \\
\hline 0 & 46.78 & 340.998 & 1300.72 & 3528.72 & 2835.85 \\
5 & 46.74 & 340.258 & 1303.61 & 3516.50 & 2853.30 \\
10 & 46.63 & 337.832 & 1312.35 & 3479.12 & 2908.16 \\
\hline
\end{tabular}

TABLE A10. (Continued)

\begin{tabular}{cccccc}
\hline \hline VZA & $a_{0}$ & $a_{1}$ & $a_{2}$ & $a_{3}$ & $a_{4}$ \\
\hline 15 & 46.45 & 333.755 & 1327.14 & 3415.32 & 3000.58 \\
20 & 46.19 & 327.851 & 1348.29 & 3322.40 & 3136.22 \\
25 & 45.89 & 319.890 & 1376.27 & 3196.93 & 3316.69 \\
30 & 45.53 & 309.535 & 1411.77 & 3033.25 & 3549.80 \\
35 & 45.15 & 296.545 & 1455.70 & 2824.01 & 3843.27 \\
40 & 44.77 & 280.419 & 1509.18 & 2559.27 & 4205.31 \\
45 & 44.45 & 260.230 & 1573.75 & 2224.71 & 4649.17 \\
50 & 44.27 & 235.930 & 1651.20 & 1800.79 & 5182.46 \\
55 & 44.44 & 206.470 & 1743.43 & 1260.13 & 5815.01 \\
60 & 45.32 & 172.349 & 1850.93 & 571.086 & 6520.36 \\
65 & 47.79 & 137.492 & 1968.16 & -288.896 & 7177.96 \\
\end{tabular}

TABLE A11. NOAA-16.

\begin{tabular}{rccccc}
\hline \hline VZA & $a_{0}$ & $a_{1}$ & $a_{2}$ & $a_{3}$ & $a_{4}$ \\
\hline 0 & 48.05 & 358.528 & 1267.12 & 3672.21 & 2571.53 \\
5 & 48.02 & 357.747 & 1269.80 & 3660.54 & 2588.48 \\
10 & 47.94 & 355.191 & 1277.91 & 3624.84 & 2641.48 \\
15 & 47.81 & 350.923 & 1291.62 & 3563.88 & 2730.87 \\
20 & 47.64 & 344.728 & 1311.22 & 3475.05 & 2861.98 \\
25 & 47.44 & 336.393 & 1337.14 & 3354.99 & 3036.66 \\
30 & 47.23 & 325.549 & 1369.97 & 3198.32 & 3262.29 \\
35 & 47.01 & 311.941 & 1410.54 & 2997.92 & 3546.41 \\
40 & 46.85 & 295.023 & 1459.83 & 2744.25 & 3897.02 \\
45 & 46.79 & 273.860 & 1519.16 & 2423.87 & 4326.18 \\
50 & 46.94 & 248.334 & 1590.04 & 2018.45 & 4840.52 \\
55 & 47.50 & 217.364 & 1673.96 & 1502.81 & 5446.94 \\
60 & 48.87 & 181.370 & 1770.87 & 849.115 & 6115.45 \\
65 & 51.89 & 144.241 & 1874.85 & 40.8346 & 6719.90 \\
\hline
\end{tabular}

TABLE A12. NOAA-17.

\begin{tabular}{rccccc}
\hline \hline VZA & $a_{0}$ & $a_{1}$ & $a_{2}$ & $a_{3}$ & $a_{4}$ \\
\hline 0 & 45.87 & 360.496 & 1309.78 & 3557.33 & 2654.88 \\
5 & 45.84 & 359.699 & 1312.58 & 3545.34 & 2672.05 \\
10 & 45.75 & 357.066 & 1321.06 & 3508.59 & 2726.20 \\
15 & 45.59 & 352.668 & 1335.39 & 3445.86 & 2817.52 \\
20 & 45.38 & 346.289 & 1355.90 & 3354.38 & 2951.72 \\
25 & 45.12 & 337.706 & 1383.04 & 3230.71 & 3130.57 \\
30 & 44.84 & 326.551 & 1417.47 & 3069.13 & 3362.07 \\
35 & 44.54 & 312.572 & 1460.09 & 2862.25 & 3654.14 \\
40 & 44.26 & 295.204 & 1511.96 & 2600.07 & 4015.54 \\
45 & 44.07 & 273.481 & 1574.56 & 2268.32 & 4459.83 \\
50 & 44.05 & 247.259 & 1649.59 & 1847.67 & 4995.12 \\
55 & 44.41 & 215.377 & 1738.76 & 1311.34 & 5631.71 \\
60 & 45.54 & 178.186 & 1842.27 & 629.384 & 6342.76 \\
65 & 48.33 & 139.505 & 1954.13 & -216.477 & 7005.36 \\
\hline & & & & & \\
& & TABLE A13. NOAA-18. & \\
\hline \hline VZA & $a_{0}$ & $a_{1}$ & $a_{2}$ & $a_{3}$ & $a_{4}$ \\
\hline 0 & 46.51 & 331.304 & 1317.08 & 3456.95 & 2974.72 \\
5 & 46.47 & 330.596 & 1319.96 & 3444.93 & 2991.82 \\
10 & 46.36 & 328.231 & 1328.66 & 3408.10 & 3045.79 \\
15 & 46.17 & 324.296 & 1343.37 & 3345.25 & 3136.74 \\
20 & 45.90 & 318.581 & 1364.43 & 3253.67 & 3270.29 \\
25 & 45.58 & 310.863 & 1392.30 & 3129.92 & 3448.13 \\
\hline & & & & &
\end{tabular}


TABLE A13. (Continued)

\begin{tabular}{cccccc}
\hline \hline VZA & $a_{0}$ & $a_{1}$ & $a_{2}$ & $a_{3}$ & $a_{4}$ \\
\hline 30 & 45.21 & 300.833 & 1427.67 & 2968.38 & 3678.06 \\
35 & 44.80 & 288.249 & 1471.48 & 2761.67 & 3967.71 \\
40 & 44.39 & 272.625 & 1524.84 & 2499.94 & 4325.34 \\
45 & 44.04 & 253.071 & 1589.31 & 2168.86 & 4764.11 \\
50 & 43.82 & 229.570 & 1666.70 & 1749.09 & 5290.83 \\
55 & 43.92 & 201.158 & 1758.92 & 1213.52 & 5914.25 \\
60 & 44.74 & 168.491 & 1866.40 & 531.189 & 6604.25 \\
65 & 47.14 & 135.784 & 1983.40 & -318.969 & 7232.02 \\
\hline
\end{tabular}

\section{REFERENCES}

Ba, M. B., R. G. Ellingson, and A. Gruber, 2003: Validation of a technique for estimating OLR with the GOES sounder. $J$. Atmos. Oceanic Technol., 20, 79-89.

Ellingson, R. G., and J. C. Gille, 1978: An infrared radiative transfer model. Part I: Model description and comparison of observations with calculations. J. Atmos. Sci., 35, 523-545.

— and M. B. Ba, 2003: A study of diurnal variation of OLR from the GOES Sounder. J. Atmos. Oceanic Technol., 20, 90-98.

— D. D. Yanuk, H.-T. Lee, and A. Gruber, 1989: A technique for estimating outgoing longwave radiation from HIRS radiance observations. J. Atmos. Oceanic Technol., 6, 706-711.

—, H.-T. Lee, D. Yanuk, and A. Gruber, 1994: Validation of a technique for estimating outgoing longwave radiation from HIRS radiance observations. J. Atmos. Oceanic Technol., 11, 357-365.

Gruber, A., and T. S. Chen, 1988: Diurnal variation of outgoing longwave radiation. J. Climatol., 8, 1-16.

— , R. G. Ellingson, P. Ardanuy, M. Weiss, S.-K. Yang, and S. N. Oh, 1994: A comparison of ERBE and AVHRR longwave flux estimates. Bull. Amer. Meteor. Soc., 75, 2115-2130.

Harries, J. E., and Coauthors, 2005: The geostationary Earth Radiation Budget Project. Bull. Amer. Meteor. Soc., 86, 945-960.

Jackson, D. L., J. J. Bates, and D. P. Wylie, 2003: The HIRS pathfinder radiance data set (1979-2001). Preprints, 12th Conf. on
Satellite Meteorology and Oceanography, Long Beach, CA, Amer. Meteor. Soc., P1.8.

Jacobowitz, H., L. L. Stowe, G. Ohring, A. Heidinger, K. Knapp, and N. R. Nalli, 2003: The Advanced Very High Resolution Radiometer Pathfinder Atmosphere (PATMOS) climate dataset: A resource for climate research. Bull. Amer. Meteor. Soc., 84, 785-793.

Lee, H.-T., A. Gruber, and R. G. Ellingson, 2004a: Inter-satellite calibration of HIRS outgoing longwave radiation data. Preprints, 13th Conf. on Satellite Meteorology and Oceanography, Norfolk, VA, Amer. Meteor. Soc., P6.3.

— A. Heidinger, A. Gruber, and R. G. Ellingson, 2004b: The HIRS outgoing longwave radiation product from hybrid polar and geosynchronous satellite observations. Adv. Space Res., 33, 1120-1124.

NOAA, cited 2006a: NOAA Polar Orbiter Data (POD) user's guide. [Available online at http://www2.ncdc.noaa.gov/docs.]

_ cited 2006b: NOAA KLM user's guide. [Available online at http://www2.ncdc.noaa.gov/docs.]

Ohring, G., A. Gruber, and R. G. Ellingson, 1984: Satellite determinations of the relationship between total longwave radiation flux and infrared window radiance. J. Climate Appl. Meteor., 23, 416-425.

Warner, J. X., and R. G. Ellingson, 2000: A new narrowband radiation model for water vapor absorption. J. Atmos. Sci., 57, 1481-1496.

Wielicki, B. A., B. R. Barkstrom, E. F. Harrison, R. B. Lee III, G. L. Smith, and J. E. Cooper, 1996: Clouds and the Earth's Radiant Energy System (CERES): An Earth Observing System experiment. Bull. Amer. Meteor. Soc., 77, 853-868.

Wong, T., B. A. Wielicki, R. B. Lee III, G. L. Smith, K. A. Bush, and J. K. Willis, 2006: Reexamination of the observed decadal variability of earth radiation budget using altitudecorrected ERBE/ERBS nonscanner WFOV data. J. Climate, 19, 4028-4040.

Young, D. F., P. Minnis, D. R. Doelling, G. G. Gibson, and T. Wong, 1998: Temporal interpolation methods for the Clouds and the Earth's Radiant Energy System (CERES). J. Appl. Meteor., 37, 572-590. 